\title{
The Effects of Service Quality and Word of Mouth on Customer Acquisition, Retention and Usage
}

\author{
Sungjoon Nam \\ Puneet Manchanda \\ Pradeep K. Chintagunta ${ }^{1}$
}

June 2006

This version: March 2007

1 Sungjoon Nam is a doctoral student, Puneet Manchanda is Associate Professor of Marketing and Pradeep K. Chintagunta is Robert Law Professor of Marketing, all at the Graduate School of Business at the University of Chicago. The authors would like to thank Don Lehmann, Hongsuk Yang, seminar participants at the MSI/USC 2007 Conference, University of Chicago, the Wharton School, the University of Missouri-Columbia, the London Business School 2006 Summer Camp and at the 2006 Marketing Science conference in Pittsburgh for valuable feedback, an anonymous firm for providing the data and Sridhar Narayanan, Hongju Liu, and Neal Rich for help with the data. All three authors would like to acknowledge research support from the Kilts Center for Marketing at the University of Chicago. Manchanda would also like to acknowledge research support from the True North Communications Faculty Research Fund. All correspondence may be addressed to authors at snam2@ChicagoGSB.edu (Nam), puneet.manchanda@ChicagoGSB.edu (Manchanda) and pradeep.chintagunta@ChicagoGSB.edu (Chintagunta). Correspondence by mail can be sent to Manchanda at 5807 S. Woodlawn Ave., Chicago, IL 60637. 


\begin{abstract}
This paper documents the existence of the direct and indirect (via word-of-mouth) effects of service quality on new customer acquisition, usage and retention using behavioral data from the launch of a new video on demand type service. For this technology, service quality the quality of the signal determining the number of movies available for viewing - is exogenously determined and objectively measured. This information, coupled with location and neighborhood information for each subscriber allows us to measure both the direct and indirect effects of service quality. Our identification strategy for these effects arises from both the main effect of neighbors who have previously adopted and the interaction between the number of neighbors and their realized service quality, while controlling for other geographic and demographic covariates.
\end{abstract}

We find a direct effect of service quality on rental usage and termination behavior. In addition, we find that word of mouth affects about one-fifth of the subscribers with respect to their activation behavior. However, this indirect effect of service quality acts as a double-edged sword as it is asymmetric. We find that the effect of negative word of mouth is twice as high as the effect of positive word of mouth for consumers influenced by word of mouth. We find these effects after controlling for unobserved heterogeneity, marketing activity, distance to retail and demographics.

Consumers affected by word of mouth tend to be heavy users once they adopt the service. The implication from these results is that service quality is important for new customer acquisition in the sense that the heavy users tend to be acquired by word of mouth rather than advertising. In terms of profitability, we find that a $10 \%$ increase in service quality leads to a $7 \%$ increase in customer lifetime value. Finally, for our sample of adopters, we find that word of mouth effects also lead to acceleration in adoption behavior.

Keywords: Services, New Products, Service Quality, Word of Mouth, Contagion, High Technology, Hazard Models 


\section{Introduction}

In any service industry, a critical decision for a firm is the determination of the appropriate level of service quality. When customers are not satisfied with a service, they are not only likely to terminate the service but also to relate their unfavorable service experience to others resulting in decreased current and potential sales (Keaveney 1995, Richins 1983). To retain existing customers and acquire new customers, firms invest huge resources to improve service quality. However, pursuing the highest level of service quality often costs too much. Anderson, Fornell and Rust (1997) have shown that the relationship between customers' satisfaction a measure of service quality - and a firm's profitability tends to be negative in service industries. For managers, it is therefore essential to understand the effects of improving the level of service quality on current and potential customer relationships.

This paper quantifies the effect of service quality on acquisition, retention and usage, while accounting for the possible spillover effects arising via word of mouth interactions between current customers and potential subscribers. We use a new, behavioral dataset that contains not only an objective and exogenous measure of service quality, but also household level information on factors that could influence spillover effects. Since a subscriber cannot observe the service quality she will obtain prior to adoption of the service, we investigate whether service quality has a direct effect on customer retention and usage behaviors. In addition, we also investigate whether the service quality level spills over and influences new customers' activation behavior via word of mouth interactions with current customers who experience the service quality post-adoption. We call this the indirect effect of service quality. Using our objective measure of service quality, we test to see if these indirect effects are asymmetric for "good" versus "bad" service quality. This is because previous literature has suggested that negative spillover has a bigger impact on a potential customer's activation behavior. The existence of the indirect effect has been hypothesized to exist in theory and has been shown using survey data but has not been tested using actual behavioral data (Anderson 1998). Since it is hard to measure service quality and even harder to ascertain whether the current customers actually communicate with potential new customers, the indirect effect of 
service quality is difficult to quantify. By contrast, the features of our data enable us to measure this effect.

The data we use in this paper are collected from the launch of a new video on demand service that requires activation, monthly maintenance and rental fees. The data span a period from October 2003 to November 2004 and come from three different geographic markets. The service - which we will refer to as DirectMovie ${ }^{2}$ does not require any physical connection to a cable service or to the Internet. The digital movie signals are transmitted from terrestrial TV towers using spare television broadcast bandwidth, usually that of a local PBS station. These signals are then decoded by a set-top box that we will refer to as the DirectMovie player (DMP). Besides the decoder, the DMP contains a hard drive allowing it to store up to one hundred titles in its hard drive. Every week, ten new movies are broadcast and the DMP updates its assortment by adding these ten movies and dropping the ten "oldest" movies. The quality of the update is a function of the strength of the TV signal received by each DMP. In other words, the weaker the signal that is delivered to the DMP, the fewer the number of movies that get updated. ${ }^{3}$

One unique feature of the data set is that it records a subscriber's TV signal quality level. This is obtained by the firm from the DMP, which is connected to the firm's main server through the phone line. This recording enables us to measure each subscriber's service quality level. If a subscriber receives a lower quality TV signal, she might not have access to all the new movies that would have been available if the updating process had been carried out. Her choice set would then be limited to past movies (that she might already have seen), thus degrading the quality of her experience with the DirectMovie service. We use signal quality as an objective measure of service quality for this video on demand service. ${ }^{4}$ Further, the level of signal quality is "exogenous" to the subscriber as she can neither pick a level of service quality (as is typical in the services literature) nor can she influence the

\footnotetext{
2 Due to confidentiality reasons, we cannot reveal the actual name of the service.

${ }^{3}$ Note that the signal quality only affects whether a movie was downloaded or not. It does not affect the picture quality of the downloaded movie. In other words, a movie is downloaded only if signal quality is above some threshold. This is confirmed by the observation that, conditional on a movie being downloaded, consumers are very satisfied with the picture quality (we provide details on this later).

${ }^{4}$ Based on subscriber feedback, the major determinant of service quality and satisfaction with DirectMovie is the objective signal quality received by a specific household. Thus, we use the terms service quality and signal quality interchangeably throughout the paper (more details on this later).
} 
level of quality received. As we discuss later, this feature of the data is critical for the identification of the indirect (word-of-mouth) effect.

Another unique feature of the data set is that it contains the street level addresses of all subscribers. This allows us to test for the existence and magnitude of spillover (word of mouth) effects. These street level addresses are converted into distance measures among customers. These inter-household distances are then used as proxies for social interaction and its effect on customers' adoption behavior (Conley and Topa 2005, Bell and Song 2004, Manchanda, Xie and Youn 2004). Note that, as described above, the key to the identification of the direct and indirect effect of service quality is that received signal quality by a household is exogenous to and idiosyncratic for that household. Even if households are located close to one another, they are "endowed" with different levels of signal quality. ${ }^{5}$ Thus, our identification strategy for these effects arises from both the main effect of neighbors and the interaction between the number of neighbors and their realized service quality, while controlling for other geographic and demographic covariates. The main effect can be seen if a higher number of (subscribing) neighbors leads to a higher probability of adoption for a household. The interaction effect implies that more neighbors with higher (lower) signal quality will lead to a higher (lower) probability of adoption. Given the independent and exogenous variation in signal quality for each household, this interaction allows us to quantify the indirect effect of signal quality. In other words, the mechanism that allows us to obtain a statistically significant interaction is that of information spillover about signal quality in a local neighborhood. Note that we use the label "word of mouth" for this spillover even though we do not have direct observations on inter-subscriber communication. This is because potential subscribers do not have any information about their realized service quality prior to adoption (we discuss this in the detail later). However, given our data, other labels - "neighborhood effects" or "geographic contagion" - could also be used.

We find evidence for both the direct effect (on retention and usage) and the indirect effect (on acquisition). Specifically, we find that $19 \%$ of new subscribers are

\footnotetext{
5 The service quality received by a specific DMP is a function of the geospatial and line-of-sight characteristics of the subscriber's residence with respect to the nearest terrestrial TV tower. Thus, two subscribers who are neighbors could receive different signal qualities if, for example, one subscriber had a tall tree while the other does not, or if one subscriber's TV room faces north versus south.
} 
affected by spillover effects from current subscribers and that these subscribers are the most responsive to possible service quality improvement. Interestingly, the magnitude of this indirect effect of service quality is comparable to the magnitude reported by the same households when they are directly surveyed. We also find that the magnitude of the negative word of mouth effect is greater than that of the positive word of mouth effect. Finally, we quantify the benefits of increasing service quality using the customer lifetime value metric. Our results show that while the word of mouth effect only affects $19 \%$ of all subscribers, these subscribers account for $36 \%$ of the additional revenue created when service quality is improved.

The paper is organized as follows. In the next section, we describe the data. We then describe the model in Section 3. Section 4 has the results and in Section 5 we quantify the benefits of increasing service quality for the firm via a counterfactual simulation. We conclude in section 6 .

\section{Data}

In this section, we describe the service, the firm's marketing activity and its subscriber base. We then explain why we consider service quality to be synonymous with signal quality and how it affects subscriber usage and retention behavior. Finally, we provide details on how we use the data in order to be able to measure the indirect or word of mouth effect of service quality.

\subsection{Service Description, Subscriber Base and Marketing Activity}

The data come from a large entertainment company that tested a video on demand type movie rental service named DirectMovie from October 2003 to November 2004. The service was provided in three test markets: Jacksonville, FL, Salt Lake City, UT and Spokane, WA. A total of 4,772 subscribers activated the service across the three markets. Jacksonville had the highest penetration ratio (0.2\%) and accounted for $45 \%$ of total subscribers followed by Salt Lake City at 44\% (Table 1). The data include household level subscription, termination and usage information. The data contain the subscription and termination date of the service for each customer as well as the usage of the service (when a consumer ordered a movie). Each subscriber

paid a one-time activation fee of $\$ 29.99$ and a monthly subscription fee of $\$ 7.99$. The 
rental fee was $\$ 3.99$ for a new release and $\$ 2.49$ for an old movie. The rental pattern across all households and time periods ${ }^{6}$ shows that a small number of movies generates a disproportionate amount of revenue, with the top $8 \%$ of movies generating $33.4 \%$ of the total revenue from rentals. This suggests that a majority of titles are not rented very frequently. Movies are usually also rented quickly - most movies get about $60 \%$ of their total revenues in the month after their release. ${ }^{7}$

The primary marketing instrument used by the company to acquire new customers was television advertising. A notable feature of the advertising expenditure was that the temporal pattern of expenditure was identical in all three markets. The advertising was of two types - the majority was conventional spot TV advertising (mean monthly spend $\$ 282,000$ with a standard deviation of $\$ 111,000$ ) and Direct Response TV (DRTV) ${ }^{8}$ advertising (mean GRPs at 0.83 with a standard deviation of 0.14). Finally, we also have access to a small survey that was administered to a subset of subscribers. The survey data are based on responses from 304 randomly chosen respondents across all three markets.

For our analysis, we removed households with incomplete or missing data and were left with 3651 subscribers. ${ }^{9}$ We then supplemented these data with demographic information (income, age, cable access, Internet access, education, marital status, number of children, number of teenagers, and race) from the 603 census tracts across the three markets. The demographics for our subscribers show a mean income of $\$ 62,297$, mean age of 32 years, with the mean number of children and teenagers at 0.65 children and 0.51 respectively. $15 \%$ of the population is over 55 years old, $19 \%$ is single, and $7 \%$ is black. $19 \%$ have cable and $13 \%$ have at least a bachelor's degree, and 17\% have Internet access. Table 2 provides demographics

\footnotetext{
${ }^{6}$ At the individual subscriber level, the data contain details on when a subscriber watched a movie. However, we only have partial information on the movie title that was watched. In addition, the firm was unable to supply us a complete set of titles available in the DMP at the subscriber level.

${ }^{7}$ At the time of our data, movies were available on DirectMovie a month after the movie was released on DVD.

${ }^{8}$ DRTV advertising essentially refers to television programs popularly known as "infomercials." As this is a medium that is clearly different from TV advertising - the program/ad durations are much longer, the content includes product demonstration and consumers can respond directly to the advertiser - we treat these two as different marketing instruments even though both are delivered via television. In addition, the company switched most of its advertising from network TV advertising to DRTV in months 11 through 14 .

${ }^{9}$ We did not find any systematic demographic differences between households for which the data were complete and those for which the data were incomplete.
} 
information on these subscribers in addition to the time to activate (since launch), time to terminate and (rental) usage.

\subsection{Service Quality and Signal Quality}

As noted earlier, the number of movies that get updated every week is determined by the signal quality received by the DMP that week. We define service quality for this product as being synonymous with signal quality. This is based on two reasons. First, the behavioral data for the households in our data suggests that signal quality is a strong predictor of usage and termination (details below). Second, we used the survey data to verify that the biggest variance in response across all items of service quality was for the item related to movie assortment (a proxy for signal quality as consumers did not observe the direct signal quality). The coefficient of variation for this measure of service quality was three times as high as that on any other item. In addition, subscribers were generally very satisfied with all aspects of the service except for signal quality. On a scale of 1 to 10 (with 10 being most satisfied), the mean score on DirectMovie's convenience was 9.5 and picture quality was 9.3. In contrast, the mean satisfaction score for movie assortment was much lower at 6.2. We also verified that the respondents were indeed able to recognize that their assortment had been updated by running a logistic regression on their response to the question whether all 10 movies were updated every week on their received signal quality. We found that that the coefficient on signal quality was highly significant $(t$ stat 4.12). Taken together, these findings suggest that our assumption that signal quality appears to be synonymous with service quality is reasonable.

The data include street level address information of each household in the area. We also collect street level address information for consumer electronics retailers that were demonstrating and selling subscriptions to DirectMovie and DMPs (Best Buy, Circuit City and Sound Quality), DVD rental shops and major shopping malls using each retailer's web site and Google Maps. We then use this spatial information to compute the distance (using Geographical Information System software) between 
subscribers and consumer electronics retailers, rental shops, and major shopping malls. ${ }^{10}$ Table 2 provides more detail on these distances.

As described in the introduction, the data include a measure of the signal quality received by the DMP. Recall that this reflects the strength of the terrestrial TV signal received by the DMP. The signal quality has a range from 0 to 2.4 and varies across and within households. Figure 1 shows the means and standard deviations of signal quality across households. The fact that the signal varies within household helps classify DirectMovie as a service. In other words, if the signal quality was constant over time for a given household (while being different across households), it could be argued that DirectMovie is more like a product rather than a service. In general, the higher the signal quality received by a household, the lower is the variation in this quality (the correlation between the mean and standard deviation of signal quality across households is -0.29).

A unique feature of this signal quality is that there is a lot of variation across geographic locations. Figure 2 shows the household locations and their signal quality levels for the Jacksonville market. As can be seen from the figure, the signal quality is subscriber-specific, not location-specific. This is also reflected at a "coarser" geographic level. Specifically, the level of variation of signal quality within census tracts (standard deviation of 0.183 ) is higher than the level of variation of signal quality across census tracts (standard deviation of 0.117). Thus we do not find evidence that specific geographic locations are necessarily "endowed" with better or worse signal quality.

As noted earlier, we checked to see if signal quality has a direct effect on subscribers' usage and termination behavior. First, in Figures $3 \mathrm{a}, 3 \mathrm{~b}$ and $3 \mathrm{c}$, we show the patterns of the activation, termination, and rental usage over time. For the first three months, the number of new subscribers increases slowly then decreases thereafter. In contrast, the number of terminators increases steadily over time, and

\footnotetext{
${ }^{10}$ Distance between two locations - (longitude1, latitude1) and (longitude2, latitude2) - is computed as $\left.d_{a, b}=3956 * \frac{2 \pi}{360} * \arccos [\cos (\mathrm{a} 1) \cos (\mathrm{b} 1) \cos (\mathrm{a} 2) \cos (\mathrm{b} 2)+\cos (\mathrm{a} 1) \sin (\mathrm{b} 1) \cos (\mathrm{a} 2) \sin (\mathrm{b} 2)+\sin (\mathrm{a} 1) \sin (\mathrm{a} 2)]\right)$, where a1 $=\frac{2 \pi}{360}$ latitude $1, \mathrm{a} 2=\frac{2 \pi}{360}$ latitude2, b1 $=\frac{2 \pi}{360}$ longitude1, b2 $=\frac{2 \pi}{360}$ longitude2
} 
has a peak at the end of the observation period. The total number of movie rentals increases over time, but the average number of movie rentals per subscriber tends to decrease over time.

We then relate the number of movie rentals and termination rates to signal quality. First, Figures $4 \mathrm{a}$ and $4 \mathrm{~b}$ show that the higher the signal, the more movies subscribers watch, and the less likely they are to terminate the subscription. Also, movie rentals tend to decline less for subscribers under good signals over time (Figure 4c). Second, we carry out an aggregate level regression at the census tract level for all three markets. The dependent variable is the number of rentals made by all households in that census tract during the first three months of usage from the start of service activation. The independent variables included are the corresponding average signal quality and demographics for the census tracts. From the results in Table 3, it can be seen that signal quality increases the usage level significantly. A $10 \%$ increase in signal quality results in 0.89 more rentals per census tract for the first three months. Thus, prima facie, signal quality seems to play a crucial role in creating revenues from existing customers through more movie rentals and longer monthly maintenance fees.

In summary, our modeling approach exploits five aspects of signal quality that we observe in the data. First, signal quality is exogenous as far as the household is concerned. Second, while the firm can raise average signal quality, it cannot target increases in this quality for a household. Third, there is variation in signal quality across and within households over time. Fourth, there is little spatial correlation in signal quality. Finally, a consumer cannot observe signal quality till she subscribes hence it is very likely that she will base her expectation of her own service quality on her neighbors' service quality. Our hypothesis is that this expectation will most likely be formed as an outcome of word of mouth communication. We discuss this below and also when we describe the covariates of our adoption model.

\subsection{The Indirect Effect of Signal Quality}

Based on a large literature that has documented the existence of word of mouth effects, typically using macro-data (see Sultan, Farley and Lehmann 1990), we expect to find these effects given our individual level data. Specifically, besides the 
direct effects, when the service satisfies current subscribers, it is likely that they would recommend it to other potential subscribers. The survey data suggest that, of the households surveyed, $86 \%$ reported that they discussed the service with someone they knew, suggesting that there are likely to be word of mouth effects. However, these indirect effects may be confounded with other effects such as those arising from marketing activity. For example, 50\% of the survey respondents replied that they heard about the service through TV advertising. Thus we need to control for such factors.

A potential manifestation of the above word of mouth effect could be spatial correlation in the adoption pattern, i.e., a household living close to one that has previously adopted is more likely to also adopt the service. ${ }^{11}$ However, an alternative explanation for such a finding could be that adoption patterns are spatially correlated due to the presence of some unobserved common geographic characteristic (referred to as "correlated effects" in Manski 1993). If this were indeed the case, we would see evidence for adoption in geographic clusters. For example, Figure 5 (adoption pattern in a part of Salt Lake City) suggests that geographical clustering may be present in the data. ${ }^{12}$

We therefore check to see if adoption patterns can be explained by temporal variation (in advertising) and cross-sectional variation (with geographic fixed effects). We estimated a household level hazard model with time to adoption as the dependent variable and advertising and 128 geography-specific dummy variables based on zip code. Table 4 shows the results of the models with only advertising as well as a model with advertising and with geographic dummies. For the adoption model with advertising and area dummies, we find that only 6 dummy variables are significant. In addition, the BIC value does not improve when geographic (dummy) variables are added. This suggests that individual level adoption behavior cannot be explained only by common geographic characteristics.

\footnotetext{
${ }^{11}$ Given the nature of the marketing domain and the data, other approaches to inferring word of mouth effects using behavioral data can also be used (e.g., see Godes and Mayzlin 2004 for the use of online activity data).

12 Of course, it could be that observable characteristics lead to spatial correlation. Figure 6 shows the census tract level income pattern for the same area as in Figure 5. From the figure it seems fairly clear that adoption patterns are not correlated with income. In our model specification, we include all the relevant observable characteristics.
} 
Thus, it is possible that word of mouth effects could explain adoption behavior. Recall that $86 \%$ of adopters reported in the survey that they had mentioned the service to others. Our approach to test for the presence of these effects is to infer it from two sources. The first source is the presence of other adopters in a potential subscriber's "neighborhood." The second source is the realized service quality received by the adopters in the neighborhood. As mentioned earlier, as signal quality is idiosyncratic and exogenous the only source of information about the quality is from other adopters in the neighborhood. Thus we expect to see a main effect of the total number of neighbors that have previously adopted the service to influence adoption behavior. In other words the more the adopters in the neighborhood, the higher the probability of adoption. Our case for the presence of word-of-mouth effects would be considerably strengthened if the probability of adoption varies not just in the number of neighbors who have adopted but also by the type of signal received by these neighbors. In other words, we expect to see an interaction between the number of neighbors and signal quality. The interaction effect implies that more neighbors with higher (lower) signal quality will lead to a higher (lower) probability of adoption. If both the main and interaction effects are present, then our use of geographic proximity or distance as a proxy for word of mouth interaction will be validated. This is because then the only explanation for this effect would be word of mouth communication as this is the only mechanism by which a potential subscriber can learn about her neighbors' (good or bad) service quality level.

Since we do not directly observe that the current subscribers communicate with other potential subscribers, we make two assumptions to capture the role of word of mouth in the adoption (activation) model. First, we assume that every current and past subscriber in a geographic "band" (circle) around each potential subscriber communicates with the potential subscriber. Since geographically close neighbors are more likely have interactions than others, using such "band" is a common practice in the social interaction literature (see Conley and Topa 2005 for details). We choose the band to be a circle of 0.5 mile radius centered at a potential subscriber. While any choice of the band size is likely to be arbitrary, we chose this based on the typical size of a neighborhood in our markets by examining the density of housing (see Figure 7 for a satellite picture of an area in Salt Lake City with a 0.5 mile neighborhood shown in a white circle). 0.5 miles is also about 7-8 minute 
walking distance and a one minute driving distance thus making interaction relatively easy. ${ }^{13}$ We count the number of neighbors who have already activated the service within the band. At the time of activation, the mean number of existing customers for a potential subscriber is 2.52 (with a standard deviation of 4.22). We also computed the correlation between the signal quality for each subscriber and the mean signal quality received by her neighbors and found the mean correlation to be 0.06. This is consistent with our earlier observation that signal quality is subscriber specific and not location specific. Note that, by implication, we assume also that there is no communication between a potential subscriber and another user who is not in the band. While this may be a concern, our identification strategy is compromised only in the case that the communication from subscribers outside the band is perfectly correlated with communication from those inside the band. While this is not impossible, our conjecture is that it is highly improbable.

In terms of consumer behavior, as consumers are not directly aware of the signal quality (and the scale it is measured on), it is not likely that they compute a cardinal score every week. Thus, our assumption is that they evaluate the service as "good" or "bad." Thus, our second assumption is that a current subscriber's recommendation to others is dichotomous. This also turns out to be consistent with the DirectMovie service, in that, from a technical point of view, the number of movies that were updated every week was not completely linear in signal quality. By analyzing the data, we found that the biggest improvement in service quality occurred at a signal quality level of 1.0. ${ }^{14}$ Based on the above, we chose the threshold of signal quality of 1.0 i.e., if a subscriber obtains a signal greater than 1.0, she will give a positive recommendation else she will give a negative recommendation. However, as these signals can vary within household, we classify a household as a good signal or bad signal household in every time based on the usage weighted mean signal received by the subscriber up to the previous time period. Note that this measure allows for both cross-sectional and temporal variation in the quality of

\footnotetext{
${ }^{13}$ We checked the sensitivity of our results to bands of size 0.7 and 1 mile and found that our results were essentially similar.

${ }^{14}$ We regressed the number of movies updated (using the rental data as a proxy for the updating) on various signal thresholds ranging from 0.5 to 2 (recall that the signal quality is reported on a scale of 0 to 2.4). We found that a threshold of 1 had the highest explanatory power. Detailed results on these regressions are available from the authors on request.
} 
signal received in the neighborhood of potential subscribers. We then compute the proportion of the good signal neighbors (denoted as "goodsigratio") for every potential subscriber. The average goodsigratio is 0.71 (with a standard deviation of 0.36). Based on these two assumptions, we can test whether a potential subscriber's adoption behavior is significantly affected by word of mouth effects. We add an interaction term between the number of neighbor and their overall service quality to allow the word of mouth effect to be either positive or negative.

\section{Model and Specification}

In this section, we first outline our model structure and then describe the model specification.

\subsection{Model Structure}

We now describe our model for the three subscriber activities: activation, termination and rental usage. We model the time to adopt (activation) and time to terminate (termination) using a hazard model with time-varying and time invariant covariates. The number of movies rented per week (rental usage) is modeled as a count model.

For a subscription type service as DirectMovie, consumers decide whether to activate the service and then whether to terminate the service once they have activated it. We therefore model the time to adopt and time to terminate (from adoption) using the discrete time proportional hazard model (PHM) first proposed by Cox (1972). This model consists of two parts: the baseline hazard, which captures the intrinsic temporal pattern, and the covariate function that captures the influence of covariates on the baseline hazard. Based on our examination of the data patterns (see Figures 3a-b), we chose the Weibull baseline hazard for the activation model and the log-logistic baseline hazard for the termination model. The differences between Weibull and log-logistic hazards are in the underlying shapes of the baseline hazard. The Weibull baseline hazard can be flat, monotonically increasing, or monotonically decreasing, but the log logistic hazard can be monotonically 
decreasing or inverted U-shaped. These baseline hazards are widely used in the literature (Seetharaman and Chintagunta 2003). ${ }^{15}$

The baseline hazard $\left(h\left(t, X_{t}\right)\right)$ for activation is defined as the probability that a potential subscriber subscribes to the service at time $t$, given she has not activated the service till that time:

$h\left(t, X_{t}\right)=h(t) \cdot e^{X_{t} \beta}=\frac{f\left(t, X_{t}\right)}{1-F\left(t, X_{t}\right)}=\frac{f\left(t, X_{t}\right)}{S\left(t, X_{t}\right)}$

Here $f\left(t, X_{t}\right)$ denotes for the subscriber's probability of activating the service at time $t$, and $S\left(t, X_{t}\right)$ (called the survival function) is for the probability that the subscriber has not yet activated the service. The covariates $X_{t}$ (both time-varying and invariant) scale the baseline hazard up or down by multiplying the baseline hazard via $e^{X_{t} \beta}$ term. The expression for the termination hazard is analogous.

The closed form expressions for the survivor function and probability density function are

$$
\begin{aligned}
& S\left(t, X_{t}\right)=\mathrm{e}^{-\sum_{u=1}^{t} e^{X t \beta} \cdot \int_{u-1}^{u} h(w) d w} \\
& \operatorname{Pr}\left(t, X_{t}\right)=1-\mathrm{e}^{-e^{X t \beta} \int_{t-1}^{t} h(w) d w}
\end{aligned}
$$

where the hazard function has either Weibull or log-logistic form.

Weibull

$$
h(t)=\gamma \alpha(\gamma t)^{\alpha-1}
$$

$$
\text { Log-logistic } \quad h(t)=\frac{\gamma \alpha(\gamma t)^{\alpha-1}}{1+(\gamma t)^{\alpha}}
$$

Given this probability density function and survival function, we construct the likelihood function for a household $i$ as

$$
L_{i}=\prod_{v=1}^{T}\left(\operatorname{Pr}\left(v, X_{i v}\right)^{\delta_{i v}}\left[1-\operatorname{Pr}\left(v, X_{i v}\right)\right]^{1-\delta_{i v}}\right)^{\chi_{i v}}
$$

where $\delta_{i v}$ is an indicator variable which takes the value 1 if the subscriber $i$ activates the service at time $v$ and 0 otherwise. Also $\chi_{i v}$ takes the value 1 if the subscriber $i$

\footnotetext{
15 We also estimated models with a Weibull baseline hazard for activation and termination, a loglogistic baseline hazard for both activation and termination and a Weibull baseline hazard for termination and a log-logistic baseline hazard for activation. The BIC criterion supported our current choice. Details on these results are available from the authors.
} 
has not activated the service in the past and 0 otherwise. For the termination model, $\delta_{i v}$ is an indicator variable which takes the value 1 if the subscriber $i$ terminates the service at time $v$ and 0 otherwise and $\chi_{i v}$ takes the value 1 if the subscriber $i$ has not terminated the service in the past and 0 if the subscriber $i$ terminates the service or has not activated the service yet.

Since the number of movies watched by households is a non-negative integer, we model it using a count data model. Specifically, we model rental usage using a type-II negative binomial regression or NBD (Cameron and Trivedi 1986). The NBD model has two parameters which represent the mean level of usage, $\lambda_{i}$, and the variance in the level of usage, $\lambda_{i}\left(1+\frac{\lambda_{i}}{\rho}\right)$, where $\lambda_{i}(>0)$ and $\rho(>0)$ are estimated parameters. The NBD model is more flexible than the Poisson count model as it does not restrict the mean and the variance to be equal. The probability density of rental usage for household $i$ is given as equation (6) where $\Gamma$ stands for a gamma function. The likelihood can be written as equation (7).

$$
\begin{aligned}
& \operatorname{Pr}\left(\mathrm{Y}_{\mathrm{i}}=\mathrm{y}_{\mathrm{i}} \mid X_{\mathrm{i}}\right)=N B D\left(\rho, \lambda_{\mathrm{i}}\right)=\frac{\Gamma\left(\rho+y_{i}\right)}{\Gamma\left(1+y_{i}\right) \Gamma(\rho)}\left(\frac{\lambda_{i}}{\lambda_{i}+\rho}\right)^{y_{i}}\left(\frac{\rho}{\lambda_{i}+\rho}\right)^{\rho} \\
& \log \left(\lambda_{i}\right)=\mathrm{X}_{\mathrm{i}}^{\prime} \beta \\
& L_{u i}=\prod_{t=1}^{T} \operatorname{Pr}\left(\mathrm{y}_{\mathrm{i}, \mathrm{t}} \mid X_{i, t}\right)
\end{aligned}
$$

To account for the unobserved heterogeneity across consumers in the baseline hazards, usage rental levels, and subscribers' sensitivities to covariates, we use a mass point distribution for these parameters and then estimate the supports and probability masses for the distribution from the data (Heckman and Singer 1984). The heterogeneity distribution is across all three of the households' decisions and so we maximize the sum of three log-likelihoods associated with activation, termination and usage. The likelihood for activation, termination, and rental usage are expressed in equations (8), (9) and (10) respectively. The integrated likelihood is summarized in equation (11). 


$$
\begin{aligned}
& L_{a i}\left(\theta_{a m} \mid X_{a i}\right)=\prod_{v=1}^{T}\left(\operatorname{Pr}_{a m}\left(v, X_{a i v}\right)^{\delta_{a i v}}\left[1-\operatorname{Pr}_{a m}\left(v, X_{a i v}\right)\right]^{1-\delta_{a i v}}\right)^{\chi_{a i v}} \\
& L_{t i}\left(\theta_{t m} \mid X_{t i}\right)=\prod_{v=1}^{T}\left(\operatorname{Pr}_{t m}\left(v, X_{t i v}\right)^{\delta_{i v}}\left[1-\operatorname{Pr}_{t m}\left(v, X_{t i v}\right)\right]^{1-\delta_{i i v}}\right)^{\chi_{a i v}} \\
& L_{u i}\left(\theta_{u m} \mid X_{u i}\right)=\prod_{v=1}^{T} \operatorname{Pr}_{u m}\left(y_{i v} \mid X_{u i v}\right) \\
& L_{i}\left(\theta_{m} \mid X_{i}\right)=L_{a i}\left(\theta_{a m} \mid X_{a i}\right) \cdot L_{t i}\left(\theta_{t m} \mid X_{t i}\right) \cdot L_{u i}\left(\theta_{u m} \mid X_{u i}\right) \\
& L=\prod_{i=1}^{N} \sum_{m=1}^{M} L_{i}\left(\theta_{m} \mid X_{i}\right) \pi_{m}
\end{aligned}
$$

We carry out the estimation using the $\mathrm{R}$ software package.

\subsection{Model Specification}

We now describe the model specification for the three sub-models (a detailed list of all the explanatory variables can be found in Table 5). As described earlier, activation of the service could be a function of marketing activity by the firm, word of mouth effects or household demographics. For marketing activity, we include the aggregate level of conventional TV and DRTV advertising as time varying covariates. For word of mouth, we include the main effect of number of neighbors and the interaction effect between number of neighbors and the proportion of neighbors with a good signal. For demographics, we use the distance to the nearest (electronics) retail store, distance to the nearest DVD rental store, the distance to the nearest mall, ${ }^{16}$ and census tract level demographics. The distance to the nearest (electronics) retail store would represent the degree of access to the retail shop where consumers can see the demonstration of the service and can activate the service. The distance to the nearest rental shop and to the nearest shopping mall is used to model other shopping/renting/movie viewing options. As census tract demographics may not capture all differences across the three markets, we also include market specific fixed effects.

Rental usage is a function of signal quality and demographics. For signal quality, we used the most recent level of signal quality received by a given household prior to the current time period (i.e., we use signal quality with one lag). We found a

\footnotetext{
${ }^{16}$ Based on the Google Local classification, we include 24 major shopping malls around Jacksonville, 21 around Salt Lake City and 11 around Spokane.
} 
few observations in our data where the signal was coded as "missing." We therefore included this as a separate dummy variable. ${ }^{17}$ To ensure that the (potentially negative) word of mouth from terminators is not excluded after termination, we retain the role of each terminator i.e., if in her last period the terminator had a signal above the threshold, then she is classified as a potentially providing positive word of mouth, else she is classified as providing negative word of mouth. As before, we include census tract level demographics and market specific fixed effects, and the distance to the nearest retail store, DVD rental shop, and mall. Finally, as rentals generally decrease over time, we included a household specific covariate that captured time (in months) since service activation.

For the termination decision, we use signal quality and demographics as in the usage model. Given that the typical consumer stays with the service for about nine months (Table 1), word of mouth is unlikely to play a role in her termination decision. This is because the consumer typically has a lot of information about her idiosyncratic service quality over time and hence does not need to rely on word of mouth. ${ }^{18}$

\section{Results and Discussion}

Table 5 shows the estimation results for the activation, termination and usage behaviors. We find significant heterogeneity in the estimated baseline hazards, mean usage level and the effects of covariates for the three decisions. Using the BIC fit criterion, we chose the three "segment" solution. Each column shows the segment specific parameters associated with baseline hazards and time covariates. The parameters for the (pooled) demographic variables are in the fourth column. The first 16 rows show the results for the activation model, rows 17 to 30 for the termination model and the remaining for the usage model.

We classify each subscriber into one of three segments using the maximum posterior probability rule (Kamakura and Russell 1989). The demographics of these

\footnotetext{
17 Our discussion with the company suggested that a "missing" signal was most probably recorded when the signal quality was very poor i.e., at 0 . This was confirmed by the rental patterns in the data essentially there was no rental activity in these weeks. However, instead of coding this as signal level 0 , we decided to separate this out as a dummy variable.

${ }^{18}$ As a check, we also estimated a model where word of mouth could potentially explain the termination decision. However, we found that word of mouth had no significant effect on the termination decision.
} 
three segments are described in Table 6. Segment 1, with smallest mass (19\%), has the lowest mean annual income $(\$ 61,921)$ and highest African-American ratio $(8.2 \%)$. In contrast, Segment 3, with $31 \%$ of the mass, has the highest income $(\$ 66,145)$ and lowest African-American ratio (3.5\%). The demographics for Segment 2, the largest with mass at $48 \%$, are between those of Segment 1 and Segment 3.

Figures $8 \mathrm{a}, 9 \mathrm{a}$ and 10a show the estimated baseline hazards for activation and termination behavior and the fitted usage pattern over time by segment. Figures $8 \mathrm{~b}, 9 \mathrm{~b}$ and $10 \mathrm{~b}$ show the empirical pattern of activation, termination and usage in the data for each segment over time. As can be seen from the figures, the estimated baseline hazards capture the general pattern on activation and termination quite well. Recall that these are baseline hazards and do not include the effect of the covariates. We first discuss the estimated baseline hazards and usage level by segment and then the effects of the time covariates.

The activation hazard associated with the Segment 1 and Segment 3 is increasing in a concave fashion over time, but the baseline hazard associated with Segment 2 is constant over time. The magnitude of the hazard for Segment 2 is also slightly lower than for the other segments (Figure 8). For the termination model, Segments 2 and 3 have almost constant baseline hazards, but the baseline hazard of termination for Segment 1 declines sharply over the first 6 months and then flattens out (Figure 9).

The mean level of initial usage is estimated to be $8.18,2.41$ and 3.89 movies a month for the first, second and third segments respectively and tends to decline over time (Figure 10). Interestingly, Segment 1, which tends to watch twice or thrice as many movies as the other two segments, has a higher termination rate than those segments. Heavy movie watchers such as those in Segment 1 may not be satisfied with the variety of the movie selection compared with those of DVD rental shops because DirectMovie service can update at most 10 movies per week and new movies have a one month lag time compared to those in DVD rental shops. The dissatisfaction with the service for this segment is supported by the observation that the termination hazard peaks very early at thirty days.

We now turn to the effect of the covariates on the hazard and usage. We first focus on the results for the activation model. The indirect effect of service quality is found only for Segment 1 (with $19 \%$ of the mass). In other words, a potential 
subscriber's adoption behavior in this segment is significantly affected by the number of neighbors and their overall service quality. The fact that both the main effect of number of neighbors and the interaction effect between the number of neighbors and the signal quality are significant provides strong evidence for the presence of a word of mouth effect. These findings also suggest support for using geographic proximity as a proxy for word of mouth effects.

The total effect of word of mouth can be computed by adding the coefficients of the number of neighbors and the interaction terms at the mean level of good signal neighbors. Given that the mean proportion of good signal neighbors is 0.71 , the total effect of word of mouth is positive on average. A closer examination of these coefficients also suggests that the magnitude of a negative word of mouth effect is twice as large as that of a positive one. In other words, when all of the neighbors have bad signal quality, the marginal effect of a current subscriber on a potential subscriber in her neighborhood is to decrease the monthly adoption probability by $13.7 \%$. In contrast, when all the neighbors have good signal quality, the marginal effect from a current subscriber on a potential subscriber is to increase the monthly adoption probability by $7.5 \%$. These results are consistent with the theory that predicts that word of mouth would have a positive effect on others' behaviors if the customers' satisfaction levels are above a certain threshold and likewise have a larger negative effect when consumers' satisfaction levels are below that same threshold (Anderson 1998).

As had been noted earlier, the firm has been able to improve its service quality over time. This has both a direct and indirect benefit. Let us focus on the indirect effect. For example, if the firm improved its quality by $10 \%$ (the data suggest that this is possible), then the indirect effect would be enhanced as the proportion of good signal subscribers would increase leading to a bigger interaction effect. Applying this $10 \%$ increase to the data, we see that it would increase the mean good signal ratio from 0.71 to 0.81 . This would then increase a potential subscriber's adoption probability by $5.44 \%$ (given that average number of neighbors is 2.5 at activation time). This effect would then magnify over time as the incremental new subscribers would then convert more potential subscribers via both the direct and indirect effects. Therefore, improvement in service quality effectively facilitates new customer acquisition via the word of mouth effect. 
Advertising also helps in customer acquisition. A $\$ 100,000$ increase in network TV advertising spending and a 10 point increase in Gross Rating Points (GRP) delivered via DRTV increases a potential subscriber's monthly adoption probability by $0 \%$ and $2.3 \%, 5.7 \%$ and $2.8 \%$ and $7.0 \%$ and $2.3 \%$ for Segments 1,2 and 3 respectively. Interestingly, the segment that is affected by word of mouth effect (Segment 1) is not affected by conventional TV advertising. Although about $60 \%$ of consumers activated the service via the phone and/or the Internet, activation behavior is affected significantly by the distance to the nearest consumer electronics retailer. When a subscriber lives 1 mile farther from the nearest retailer the monthly activation rate decreases by $1.8 \%$. Consumers who have easier access to the retailer might active the service with lower uncertainty by seeing the display of the service in the retailer. In terms of demographics, we find that households in census tracts with higher mean annual income are more likely to adopt. For every additional $\$ 10,000$ in a household's mean annual income, the adoption probability increases by $4.2 \%$. Finally, we do not find market specific fixed effects on activation as both the Salt Lake City and Spokane fixed effects are not significantly different from zero in the activation model (Table 5).

We now turn to the usage model. Broadly speaking, the results are similar across all three segments. Higher service quality promotes higher rentals over time (Figure 11). A 10\% increase in signal quality increases the monthly rental usage by $3.2 \%, 3.7 \%$, and $2.1 \%(0.72,0.23$, and 0.22 rentals for the first three months) for Segments 1, 2 and 3 respectively. Also, as expected, the "signal missing" dummy suggests a significant drop in usage. In addition, rentals decline over time for all three segments. Surprisingly, we find no effects of distance from the nearest DVD rental store, the nearest retailer or the nearest mall on usage patterns.

Usage seems to be affected more than the other two behaviors by demographics. Households in census tracts with higher mean annual income tend to use the service less - an additional $\$ 10,000$ in a household's mean annual income leads to a $1.7 \%$ drop in usage. Additionally, a $10 \%$ increase in the population of single (never married) people, the number of children in a household, and the proportion of elderly (55+) tends to increase monthly rental usage by $4.4 \%, 2.3 \%$ and $9.9 \%$ respectively. In contrast, a $10 \%$ increase in the proportion of AfricanAmericans decreases the monthly usage by $2.5 \%$, given that other demographics are 
equal. Subscribers in Salt Lake City and Spokane watch fewer movies than those in Jacksonville by $10 \%$ and $13 \%$ respectively.

The results of the termination model are also similar across the three segments. Higher signal quality effectively lowers the termination probability for the service. A $10 \%$ increase in service quality lowers the monthly termination probability by $9.9,8.3$ and $13.0 \%$ for Segments 1,2 and 3 respectively. A missing signal also increases the termination probability. The distance to the nearest DVD rental and the nearest consumer electronics retailer (which also sells DVD titles) significantly lowers the termination rate. When a subscriber lives 1 mile farther from the nearest DVD rental shop and the nearest consumer electronics retailer (which also sells DVD titles) the monthly termination rate decreases by $7.1 \%$ and $3.3 \%$ respectively. While this is expected, it is interesting that the distance to the nearest shopping mall increases the monthly termination rate by $6.8 \%$. This may be because mall access potentially implies more time spent on shopping and less (time) on leisure activities such as watching movies, leading to quicker termination. Interestingly, these relative advantages to the outside option significantly affect the termination behavior even though these do not change the actual rental behaviors significantly. Once a subscriber has activated the service, her expected loss for termination might be bigger than the actual gain it gives to her.

For every additional $\$ 10,000$ in a household's mean annual income, the termination probability decreases by $6.4 \%$. Also, a $10 \%$ increase in the population of single (never married) people, the number of children in a household and the proportion of elderly (55+) tends to increase the termination probability by $24 \%$, $8.3 \%$ and 23\% respectively. Finally, Salt Lake City subscribers are slower to terminate relative to those in Jacksonville and Spokane.

In conclusion, we find a direct effect of service quality for termination and rental usage. The effect sizes, while not very large, are economically significant (more details on this in the next section). In addition, we find that word of mouth affects about one-fifth of the subscribers with respect to their activation behavior. Interestingly, when consumers were asked in the survey, "Do you know anyone who has signed up for Moviebeam as a result of seeing it in your home or hearing about it from you?," $21 \%$ of them replied in the affirmative. However, the word of mouth effect acts as a double-edged sword as it is asymmetric in nature. We find that the 
effect of negative word of mouth is twice as high as the effect of positive word of mouth for these consumers. The only marketing instrument used by the firm, advertising, has a positive impact on adoption.

In terms of unobserved heterogeneity, the three consumer segments are most different with respect to the activation decision. Differences across consumers in observables suggest that mean household income tends to affect all three decisions. Higher mean household income leads to quicker adoption, lower usage and lower termination. Also, consumers in Salt Lake City tend to terminate later and rent fewer movies relative to those in Jacksonville. The distance to the nearest retailer, nearest rental store and to the nearest mall has some impact on termination behavior but not on usage.

\section{The Effects of Signal Quality Improvement}

In this section, we carry out two counterfactual analyses. In the first analysis, we investigate the effect of an increase in signal quality relative to the current level of signal quality. In the first counterfactual analysis, we quantify the effect of a $10 \%$ increase in signal quality improvement on usage and termination behavior for each segment. ${ }^{19}$ In the second counterfactual analysis, we show the temporal difference in adoption patterns (for our sample of adopters) when all word of mouth effects are positive as compared to when all these effects are negative.

For the first counterfactual analysis, we need to restrict the sample to subscribers who are at or below the $90 \%$ signal level for each time period (else their signal quality will exceed the theoretical maximum). This restriction limits the number of households for our counterfactual analysis to 3066 (out of a total of 3651). We use a time period of five years to carry out the analysis and compute the value of the customer base to the firm over this time period. We set the clock to zero for each of the 3066 households i.e., all households are assumed to be subscribers at month 1.

Given that a household is a subscriber to the service, the value of the customer to the firm depends on the usage of the household and the duration that the household remains a subscriber (i.e., the time to terminate the service). Thus, we need to forecast usage and termination for the households. As noted previously,

\footnotetext{
${ }^{19}$ We used the observed data patterns to choose this number.
} 
these decisions depend upon the level of signal quality, which is not time invariant. We therefore need to make some assumptions about the signal quality process over time. We assume that the signal quality stabilizes for each household at the mean of the observed signal quality received by that household in the last three months of the data. Also, we assume that the expected rental usage would asymptote to a constant level over an 18 month period. This implies that the service provider receives the same expected rental revenue per subscriber till termination (from 18 months onwards).

To calculate the expected subscription length, we compute the termination probability for each household for each month for all sixty months. We then draw a random variable from a uniform distribution between 0 and 1 and use that as the cutoff for termination. In other words, we terminate the service for a subscriber in the first period for which the randomly generated variable is equal to or greater than the computed termination probability. We then compute the net present value of the rental revenues and monthly subscription fee (using a $0.08 \%$ monthly discount rate corresponding to a $10 \%$ annual discount rate) to obtain the "customer lifetime value" (CLV). Rental revenues are computed using the weighted average price based on current movie rentals.

We carry out the above procedure a total of 30 times. Using the 30 CLVs obtained, we generate the mean CLV for each subscriber. We then average this mean CLV across all customers in a segment to obtain the mean and standard deviation of the CLV for a representative customer in that segment.

We first discuss the results under the current signal quality (top half of Table 7). At the end of five years, we find that 2,552 out of 3,066 (or 83\%) subscribers terminate the service. The average duration of a terminator is 18.32 months. Across the three segments, the termination proportions are $0.81,0.92$ and 0.77 . The average duration that a terminator stays with the service is $9.45,19.89$, and 21.48 months for Segments 1, 2 and 3 respectively.

The average CLV for a subscriber is $\$ 289.30$. Subscribers in Segments 3 have the highest CLV, followed by those in Segment 1 and then Segment 2. For Segment 3, the high CLV comes from having the lowest termination rate i.e., the longest duration and have a relatively high usage rate. In contrast, subscribers in Segment 1 have the highest usage rate but terminate quickly. This leads to 
significantly lower revenue from the monthly subscription fee. Note that it is difficult for the firm to predict which segment will have the highest CLV as it is a function of both expected duration and rental rate.

Turning to the results when the signal quality has improved by $10 \%$, we find that 2,483 out of 3,066 (or $81 \%$ ) subscribers terminate the service. However, the average duration of a terminator is 19.02 months - an increase of $4 \%$ relative to the current level of signal quality. Across the three segments, the termination proportions are $0.78,0.91$ and 0.73 . The average duration that a terminator stays with the service is 9.89, 20.62, and 22.38 months for Segments 1,2 and 3 respectively. On average, the increase in service quality decreases the number of terminators by $3.0 \%$, extends the customer relationship by 0.70 months and increases monthly rentals by $10.2 \%$.

These behavioral changes result in a 7\% increase in average CLV ( $\$ 310.57$ versus $\$ 289.30$ ). Note that this increase is going to be understated as we truncate the revenue stream from all subscribers (terminators and survivors) after 5 years. As the number of survivors is higher when the signal quality is higher, there is likely to be incremental revenue. As can be seen from the table, about $56 \%$ of this increase comes from higher rental revenue and the balance from the monthly subscription fee.

The value of our counterfactual analysis can be seen in terms of resource allocation. If managers were to allocate resources without carrying out this experiment, they would allocate most resources to subscribers in Segment 3 which has the highest CLV. However, in terms of the additional increase in CLV by segment, we find that Segment 1 is most responsive with an increase of $11 \%$ while Segments 2 and 3 both show an increase of $5 \%$ and $7 \%$ respectively. This is primarily because the increase in service quality leads to higher usage in the early time periods (leading to a higher net present value). Another way to look at this is that $51.4 \%$ (\$39.70) of the incremental CLV comes from Segment 1 that is only $20 \%$ of the population. Thus, if managers could improve service quality selectively, they should target subscribers in Segment 1.

Note that so far we have focused on the usage and termination behavior. Given that the signal quality is higher leading to a higher proportion of good signal neighbors, consumers in Segment 1 are likely to adopt earlier as a function of this 
incremental word of mouth effect. We fix the number of neighbors as in the data, compute the new "goodsigratio" and determine the decrease in adoption time. We find that, on average, consumers in Segment 1 adopt 5 days faster (0.15 months) (Table 8). This would result in the CLV of Segment 1 being even higher than the above number. We show the difference in adoption patterns for all consumers with and without the acceleration in adoption times for Segment 1 arising from higher word of mouth in Figure 12. At its peak (month 6), the difference is an increase of about $6 \%$ in the subscriber base.

However, the activation model cannot tell us how many potential subscribers (who are not in our sample) would activate the service. This is because our sample is restricted to adopters. Therefore, we cannot quantify the indirect effect of improved service quality that measures the incremental (i.e., out of our sample) subscribers. Our activation timing simulation should therefore be seen as providing the lower bound of the indirect effect of service quality (by only focusing on the behavior of adopters).

For our second counterfactual analysis, we predict the adoption patterns over time for our sample of adopters when the good signal ratio is set to 1 as compared to a situation where it is set to zero. In other words, we want to look at the pattern of adoption when all word of mouth effects are positive as opposed to being negative. Figure 13 shows the difference in the number of subscribers who adopt over time. On average, the adoption time is reduced by 24 days ( 0.76 months). As can be seen from the figure, this difference increases over time and peaks at the eighth month (108) and decreases thereafter. At the peak (month 8), the difference represents an increase of about $17 \%$ in the subscriber base. This pattern confirms that word of mouth plays a significant part in the overall adoption process.

\section{Conclusion}

This paper contributes to the service marketing and social networking literature by showing the existence and quantifying the effect of the direct and indirect effects of service quality on new customer acquisition, usage and termination using behavioral data. We use a unique dataset describing the launch of a new high-tech, entertainment product (a video on demand type service). For this technology, service 
quality is exogenously determined and objectively measured. This information, coupled with location and neighborhood information for each subscriber allows us to measure both the direct and indirect effects of service quality.

Our identification strategy for the indirect effects arises from both the main effect of neighbors and the interaction between the number of neighbors and their realized service quality, while controlling for unobserved heterogeneity, marketing activity, distance to retail, market fixed effects and demographic covariates. The main effect can be seen if a higher number of (subscribing) neighbors leads to a higher probability of adoption for a household. The interaction effect implies that more neighbors with higher (lower) signal quality will lead to a higher (lower) probability of adoption.

We find a direct effect of service quality for rental usage and termination. In addition, we find that word of mouth (the indirect effect) affects about one-fifth of the subscribers with respect to their activation behavior. However, this effect acts as a double-edged sword as it is asymmetric - we find that the effect of negative word of mouth is twice as high as the effect of positive word of mouth for these consumers.

Consumers affected by word of mouth are heavy users once they adopt the service. This implies that service quality is important for new customer acquisition in the sense that the heavy users tend to be acquired by word of mouth rather than advertising. In terms of profitability, we find that a $10 \%$ increase in service quality leads to a $7 \%$ increase in CLV. Interestingly, as the segments differ in their activation, usage and termination behaviors, managerial judgment may lead to focusing on a segment that may look attractive with the highest CLV (Segment 3) over a segment that looks less attractive (Segment 1). However, the fact the Segment 1 consists of early adopters who use the service heavily, leads to the highest proportional increase in CLV. Finally, for our sample, we find that word of mouth effects lead to some acceleration in adoption behavior. As we do not have data on non-adopters, we can only provide this number as a lower bound.

Our research has some limitations. First, the nature of the service and our data make it hard to identify ex-ante the actual potential population for this service. Thus, we cannot quantify the effects of the change in service quality on nonsubscribers. However, it should be noted that this is a general problem for new products when the target population is unrestricted. Our data also preclude us from 
studying how the movie assortment affects usage and termination behavior. While our data suggest that service quality is synonymous with signal quality, there may be other unobserved aspects of service quality that could affect subscriber behavior. In addition, we assume that service quality affects consumers' activation, usage and termination decisions independently. While we have supplemented our data with demographics at the census tract level, we do not have detailed demographic information at the household level. Finally, we also cannot explicitly model word of mouth communication that occurs outside the geographic bands e.g., at the workplace or over electronic media. We hope that future research will be able to address these limitations.

In sum, this paper takes the first steps towards understanding how the quality of a new service affects its adoption, usage and termination. We find that improvements in quality have a direct and significant impact on profitability (CLV). We also find that the word of mouth (the indirect effect) has a significant effect on the adoption of the new service and that negative word of mouth has twice the effect of positive word of mouth. Further, we show that the firm providing the service is better off by allocating its resources towards improving the service quality of the segment who CLV is most sensitive to service quality rather than to the segment with the highest CLV. 


\section{References}

Anderson, Eugene W. (1998), "Customer Satisfaction and Word of Mouth," Journal of Service Research, Vol. 1, No. 1, August, 5-17.

Anderson, Eugene W., Claes Fornell and Roland Rust (1997), "Customer Satisfaction, Productivity, and Profitability: Differences between Goods and Services," Marketing Science, Vol. 16, No. 2, 129-145.

Bell, David R. and Sangyoung Song (2004), "Social Contagion and Trial on the Internet: Evidence from Online Grocery Retailing," Working Paper, The Wharton School, University of Pennsylvania.

Cameron, C., and P. Trivedi (1986), "Econometric Models Based on Count Data: Comparisons and Applications of Some Estimators and Tests," Journal of Applied Econometrics, Vol. 1, 29-54.

Conley, Timothy G. and Topa, Giorgio (2005), "Estimating Dynamic Local Interactions Models," Journal of Econometrics, forthcoming.

Cox, D. R. (1972), "Regression Models and Life Tables," Journal of the Royal Statistical Society, Ser. B, 34, 187-220.

Godes, David and Dina Mayzlin (2004), "Using Online Conversation to Study Wordof-Mouth Communication,” Marketing Science, 23(4), 545-560.

Heckman and Singer (1984), "A Method for Minimizing the Impact of Distributional Assumption in Econometric Models for Duration Data," Econometrica, Vol. 52, 271318.

Kamakura, Wagner A. and Gary J. Russell (1989), "A Probabilistic Choice Model for Market Segmentation and Elasticity Structure," Journal of Marketing Research, 26 (November), 379-90.

Keaveney, Susan M. (1995), "Customer Switching Behavior in Service Industries: An Exploratory Study,” Journal of Marketing, Vol. 59, April, 71-82.

Manchanda, Puneet, Ying Xie and Nara Youn (2004), "The Role of Targeted Communication and Contagion in Product Adoption," Working Paper, University of Chicago.

Manski, Charles F. (1993), "Identification of Endogenous Social Effects: The Reflection Problem,” Review of Economic Studies, Vol. 60, 531-542.

Richins, Marsha L. (1983), "Negative Word of Mouth by Dissatisfied Consumers: A Pilot Study," Journal of Marketing, Vol. 47, 68-78. 
Seetharaman, P.B. and Chintagunta, P. K. (2003), "The Proportional Hazard Model for Purchase Timing: A Comparision of Alternative Specifications," Journal of Business \& Economic Statistics, Vol. 21, No. 3, 368-382.

Sultan, F., Farley, F. and Donald Lehmann. (1990), “A Meta-analysis of Application of Diffusion Models," Journal of Marketing Research, February Vol. 27(1), 70-77. 
Table 1: Penetration ratio by market

\begin{tabular}{lccc}
\hline & Jacksonville & Salt Lake City & Spokane \\
\hline Total Population & $1,080,925$ & $1,764,891$ & 448,533 \\
Total Number of subscribers & 2,147 & 2,061 & 559 \\
Complete observations & 1,608 & 1,574 & 469 \\
Penetration ratio & $0.20 \%$ & $0.12 \%$ & $0.13 \%$ \\
\hline
\end{tabular}


Table 2: Descriptive Statistics

\begin{tabular}{|c|c|c|c|c|c|}
\hline Variables & Obs & Mean & S.D. & Min & $\operatorname{Max}$ \\
\hline Actv_date (days) & 3651 & 140.2 & 108.8 & 1 & 400 \\
\hline Term_date (days) & 934 & 253.3 & 105.4 & 16 & 405 \\
\hline Signal Quality & 3651 & 1.66 & 0.52 & 0 & 2.41 \\
\hline Usage (total rentals) & 3651 & 26.97 & 25.3 & 1 & 294 \\
\hline Longitude & 3651 & -99.27 & 15.75 & -117.8 & -81.32 \\
\hline Latitude & 3651 & 37.01 & 6.37 & 29.92 & 48.06 \\
\hline Dist_retail (miles) & 3651 & 3.64 & 3.11 & 0.01 & 28.89 \\
\hline Dist_rental (miles) & 3651 & 1.53 & 1.53 & 0.01 & 22.52 \\
\hline Dist_mall (miles) & 3651 & 3.8 & 3.49 & 0.01 & 28.07 \\
\hline Income** & 3651 & 6.23 & 2.53 & 2.49 & 18.53 \\
\hline Age $* *$ & 3651 & 31.76 & 5.61 & 15.52 & 49.21 \\
\hline Cable** & 3651 & 0.19 & 0.1 & 0 & 0.59 \\
\hline Internet** & 3651 & 0.17 & 0.03 & 0.06 & 0.27 \\
\hline Education** & 3651 & 0.13 & 0.06 & 0.02 & 0.37 \\
\hline Single** & 3651 & 0.19 & 0.06 & 0.09 & 0.8 \\
\hline Child** & 3651 & 0.65 & 0.27 & 0.09 & 1.9 \\
\hline Teenager** & 3651 & 0.51 & 0.23 & 0.16 & 3.32 \\
\hline \multirow{2}{*}{$\begin{array}{l}\text { Old** } \\
\text { Black }^{* *}\end{array}$} & 3651 & 0.17 & 0.07 & 0.01 & 0.42 \\
\hline & 3651 & 0.07 & 0.14 & 0 & 0.98 \\
\hline
\end{tabular}

** Demographic information is based on 2002 Census Tract level

Income Mean Income level $(\$ 10,000)$

Age Mean age of population

Cable the proportion of population with Cables

Internet the proportion of population with Internet access

Education the proportion of population with at least 4 year's college degree

Single the proportion of population of single (never married)

Child the proportion of children (under 13) given household

Teenager the proportion of teenagers (14 to 24) given household

Old the proportion of population over 55

Black the proportion of population of black (non hispanic) 


\section{Table 3: Aggregate Usage Result}

\begin{tabular}{lrr}
\hline & Est & S.E. \\
\hline Const & $\mathbf{1 4 . 8 1}$ & 2.64 \\
Signal Quality & $\mathbf{3 . 6 9 1}$ & 1 \\
Income (10,000\$) & $\mathbf{- 2 e - 3}$ & $5.4 \mathrm{e}-5$ \\
Income^2 (10e8\$) & $\mathbf{8 . 2 9 e - 1 0}$ & $2.79 \mathrm{e}-10$ \\
Black (\%) & $\mathbf{6 . 4 3}$ & 1.96 \\
\# of consumer & & \\
electronic shops & -0.189 & 0.79 \\
\# of DVD rental shops & -0.224 & 0.43 \\
Education (\%) & 10.76 & 7.57 \\
Cable (\%) & -5.57 & 3.39 \\
\hline
\end{tabular}

$\mathrm{R}^{2}=0.0817 \quad$ \# of obs 592

\section{Table 4: Individual level hazard(*) model}

\begin{tabular}{lcccc}
\hline & \multicolumn{2}{c}{ Ad only } & \multicolumn{3}{c}{ Ad+area dummies } \\
& Est & S.E. & Est & S.E. \\
\hline $\log (\alpha)$ & 0.07 & 0.018 & $\mathbf{0 . 1 0 3}$ & 0.017 \\
$\log (\mathrm{Y})$ & $\mathbf{- 1 . 7 4 6}$ & 0.033 & $\mathbf{- 1 . 7 9 4}$ & 0.131 \\
Ad $(\$ 100,000)$ & $\mathbf{0 . 0 5 9}$ & 0.012 & $\mathbf{0 . 0 5 1}$ & 0.012 \\
DRTV $($ GRP $)$ & $\mathbf{2 . 5 7}$ & 0.112 & $\mathbf{2 . 3 1 5}$ & 0.114 \\
\hline LL & $-8,857.6$ & & $-8,762.9$ & \\
BIC & $17,754.5$ & \multicolumn{3}{c}{$18,822.5$} \\
\end{tabular}


Table 5: Parameter Estimates

\begin{tabular}{|c|c|c|c|c|c|c|c|c|}
\hline & \multicolumn{2}{|l|}{ Seg1 } & \multicolumn{2}{|l|}{ Seg2 } & \multicolumn{2}{|l|}{ Seg3 } & \multicolumn{2}{|l|}{ Demo } \\
\hline & Est & S.E. & Est & S.E. & Est & S.E. & Est & S.E. \\
\hline \multicolumn{9}{|l|}{ Activation } \\
\hline $\log ($ Alpha $)$ & 0.173 & 0.044 & 0.053 & 0.029 & 0.114 & 0.047 & & \\
\hline $\log ($ Gamma $)$ & -1.618 & 0.205 & -1.803 & 0.218 & -1.376 & 0.208 & & \\
\hline Neighbor & -0.137 & 0.068 & 0.013 & 0.035 & 0.091 & 0.054 & & \\
\hline Nei*goodsigratio & 0.212 & 0.086 & -0.004 & 0.042 & -0.047 & 0.074 & & \\
\hline Ad $(\$ 100,000)$ & -0.026 & 0.032 & 0.055 & 0.019 & 0.068 & 0.024 & & \\
\hline DRTV (1,000GRP) & 2.242 & 0.278 & 2.787 & 0.156 & 2.281 & 0.633 & & \\
\hline Dist_retail (mile) & & & & & & & -0.018 & 0.008 \\
\hline Dist_mall (mile) & & & & & & & 0.011 & 0.006 \\
\hline Dist_rental (mile) & & & & & & & 0.008 & 0.015 \\
\hline Income $(\$ 10,000)$ & & & & & & & 0.041 & 0.008 \\
\hline Single (\%) & & & & & & & -0.472 & 0.469 \\
\hline Child (\# per HH) & & & & & & & -0.005 & 0.138 \\
\hline Old (over 55,\%) & & & & & & & -0.018 & 0.439 \\
\hline Black (\%) & & & & & & & 0.035 & 0.149 \\
\hline SLC & & & & & & & -0.085 & 0.055 \\
\hline SPK & & & & & & & -0.104 & 0.063 \\
\hline \multicolumn{9}{|l|}{ Termination } \\
\hline $\log ($ Alpha $)$ & -1.51 & 0.176 & 0.334 & 0.097 & 0.091 & 0.19 & & \\
\hline $\log ($ Gamma $)$ & -9.916 & 2.904 & -4.361 & 0.425 & -4.529 & 0.581 & & \\
\hline Signal & -0.436 & 0.127 & -0.363 & 0.163 & -0.58 & 0.191 & & \\
\hline Sigmiss & 2.207 & 0.304 & 1.191 & 0.284 & 1.31 & 0.334 & & \\
\hline Dist_retail (mile) & & & & & & & -0.034 & 0.015 \\
\hline Dist_mall (mile) & & & & & & & 0.07 & 0.013 \\
\hline Dist_rental (mile) & & & & & & & -0.074 & 0.03 \\
\hline Income $(\$ 10,000)$ & & & & & & & -0.066 & 0.017 \\
\hline Single (\%) & & & & & & & 2.2 & 0.814 \\
\hline Child (\# per HH) & & & & & & & 0.799 & 0.252 \\
\hline Old (over 55,\%) & & & & & & & 2.058 & 0.815 \\
\hline
\end{tabular}




\begin{tabular}{|c|c|c|c|c|c|c|c|c|}
\hline Black (\%) & & & & & & & -0.106 & 0.257 \\
\hline SLC & & & & & & & -0.51 & 0.107 \\
\hline SPK & & & & & & & -0.222 & 0.126 \\
\hline \multicolumn{9}{|l|}{ Usage } \\
\hline Intercept & 1.966 & 0.118 & 0.806 & 0.113 & 1.291 & 0.108 & & \\
\hline Theta & 1.058 & 0.039 & 0.787 & 0.039 & 1.741 & 0.046 & & \\
\hline Time (month) & -0.08 & 0.004 & -0.177 & 0.005 & -0.078 & 0.002 & & \\
\hline Signal & 0.13 & 0.023 & 0.151 & 0.017 & 0.086 & 0.013 & & \\
\hline Sigmiss & -4.496 & 0.262 & -2.594 & 0.092 & -0.789 & 0.044 & & \\
\hline Dist_retail (mile) & & & & & & & 0.003 & 0.004 \\
\hline Dist_mall (mile) & & & & & & & -0.004 & 0.004 \\
\hline Dist_rental (mile) & & & & & & & 0.006 & 0.006 \\
\hline Income $(\$ 10,000)$ & & & & & & & -0.017 & 0.003 \\
\hline Single (\%) & & & & & & & 0.435 & 0.207 \\
\hline Child (\# per HH) & & & & & & & 0.226 & 0.068 \\
\hline Old (over $55, \%$ ) & & & & & & & 0.943 & 0.223 \\
\hline Black (\%) & & & & & & & -0.245 & 0.077 \\
\hline SLC & & & & & & & -0.108 & 0.027 \\
\hline SPK & & & & & & & -0.145 & 0.028 \\
\hline proportion & 0.193 & & 0.477 & & 0.323 & & & \\
\hline LL & $-70,36$ & & $\mathrm{BIC}$ & & 94 & & & \\
\hline
\end{tabular}


Table 6: Demographics by segment

\begin{tabular}{lrrr}
\hline Variables & Seg1 & Seg2 & Seg3 \\
\hline Jacksonville (JSV) & 0.45 & 0.47 & 0.38 \\
Salt Lake City (SLC) & 0.40 & 0.42 & 0.47 \\
Spokane (SPK) & 0.14 & 0.11 & 0.15 \\
Dist_retail (mile) & 3.697 & 3.623 & 3.635 \\
Dist_rental (mile) & 1.562 & 1.472 & 1.600 \\
Dist_mall (mile) & 3.753 & 3.689 & 4.020 \\
Signal Quality & 1.594 & 1.654 & 1.710 \\
Income (\$) & 61,921 & 62,880 & 66,145 \\
Age (yr) & 31.7 & 31.8 & 31.7 \\
Cable penetration (\%) & 0.19 & 0.19 & 0.18 \\
Internet penetration (\%) & 0.17 & 0.17 & 0.18 \\
Education (4 yr) & 0.13 & 0.13 & 0.14 \\
Single (\%) & 0.20 & 0.19 & 0.19 \\
Child (\# per HH) & 0.64 & 0.64 & 0.66 \\
Teenager (\# per HH) & 0.51 & 0.51 & 0.52 \\
Old (over 55,\%) & 0.17 & 0.17 & 0.17 \\
Black ratio (\%) & 0.082 & 0.076 & 0.059 \\
Duration (month) & 5.23 & 5.78 & 3.5 \\
Total Rental & 12.34 & 37.78 \\
\# HH in segment & 1,762 & 1,114 \\
\hline & & & \\
\hline
\end{tabular}




\section{Table 7: Counterfactual Simulation}

\begin{tabular}{|c|c|c|c|c|c|c|c|c|}
\hline & \multicolumn{2}{|c|}{ Segment 1} & \multicolumn{2}{|c|}{ Segment 2} & \multicolumn{2}{|c|}{ Segment 3} & \multicolumn{2}{|c|}{ Avg } \\
\hline & Mean & S.D. & Mean & S.D. & Mean & S.D. & Mean & S.D. \\
\hline \multicolumn{9}{|l|}{ Termination } \\
\hline $\begin{array}{l}\text { Survival } \\
\text { duration (months)* }\end{array}$ & 9.45 & 0.50 & 19.89 & 0.30 & 21.48 & 0.48 & 18.32 & 0.24 \\
\hline \#Terminator & 479.4 & 7.8 & 1298.7 & 7.0 & 774.6 & 11.43 & 2,552 & 17.27 \\
\hline $\begin{array}{l}\text { Total revenue } \\
\text { (Monthly Subscription) }\end{array}$ & 75,552 & 3,088 & 225,108 & 3,141 & 205,473 & 4,009 & 506,134 & 5,995 \\
\hline $\begin{array}{l}\text { Per subscriber revenue } \\
\text { (Monthly Subscription) }\end{array}$ & 127.62 & & 160.11 & & 204.05 & & 168.43 & \\
\hline \multicolumn{9}{|l|}{ Rental } \\
\hline \# Rentals & 46,387 & 2,030 & 14,769 & 224 & 61,183 & 1,303 & 122,340 & 2,541 \\
\hline Rental Revenue & 143,331 & 5,908 & 47,594 & 710 & 189,928 & 3,682 & 380,853 & 7,280 \\
\hline CLV (total)** & 218,883 & 8,985 & 272,702 & 3,839 & 395,401 & 7,689 & 886,987 & 12,625 \\
\hline CLV (per subscriber) & 369.74 & & 193.96 & & 392.65 & & 289.30 & \\
\hline \multicolumn{9}{|l|}{$10 \%$ increase } \\
\hline $\begin{array}{l}\text { Termination } \\
\text { Survival } \\
\text { duration (months)* }\end{array}$ & 9.89 & 0.46 & 20.62 & 0.37 & 22.28 & 0.55 & 19.02 & 0.27 \\
\hline \# Terminators & 463.0 & 9.4 & 1283.0 & 10.3 & 736.9 & 12.0 & $2,483.0$ & 18.2 \\
\hline $\begin{array}{l}\text { Total revenue } \\
\text { (Monthly Subscription) }\end{array}$ & 82,028 & 2,923 & 234,839 & 3,656 & 217,903 & 3,691 & 534,771 & 6,030 \\
\hline $\begin{array}{l}\text { Per subscriber revenue } \\
\text { (Monthly Subscription) }\end{array}$ & 138.56 & & 167.03 & & 216.39 & & 177.96 & \\
\hline \multicolumn{9}{|l|}{ Rental } \\
\hline \# Rentals & 52,151 & 1,995 & 16,060 & 290 & 66,621 & 1,264 & 134,831 & 2,521 \\
\hline Rental Revenue & 160,364 & 5,756 & 51,499 & 838 & 205,585 & 3,575 & 417,449 & 7,158 \\
\hline $\mathrm{CLV}$ (total)** & 242,394 & 8,668 & 286,338 & 4,483 & 423,488 & 7,258 & 952,220 & 12,624 \\
\hline CLV (per subscriber) & 409.44 & & 203.65 & & 420.54 & & 310.57 & \\
\hline \# of Subscribers & 592 & & 1,406 & & 1,007 & & 3,066 & \\
\hline
\end{tabular}

All revenue numbers are in present value terms

*For a subscriber who terminates in the simulation period (five years)

** CLV is the sum of revenue from monthly subscriptions and rentals 
Table 8: Counterfactual simulation

(indirect effect of service quality)

\begin{tabular}{lcccc}
\hline & \multicolumn{2}{c}{ Activation Month } & \multicolumn{2}{c}{ Number of Activators } \\
\hline & Mean & S.D. & Mean & S.D. \\
Actual & 5.51 & & 644.0 & \\
Current Signal Quality & 5.01 & 0.13 & 695.7 & 0.92 \\
$10 \%$ Increase & 4.86 & 0.12 & 696.0 & 0.81 \\
\hline
\end{tabular}

Table 9: Counterfactual simulation

(All Good vs Bad WOM)

\begin{tabular}{llllc}
\hline & & & \\
& Mean & S.D. & Mean & S.D. \\
& & & & \\
All Good Signal Neighbors & 4.57 & 0.12 & 696.4 & 0.57 \\
All Bad Signal Neighbors & 5.33 & 0.14 & 670.8 & 4.3 \\
\hline
\end{tabular}




\section{Figure 1: Signal quality distribution}

Mean across households

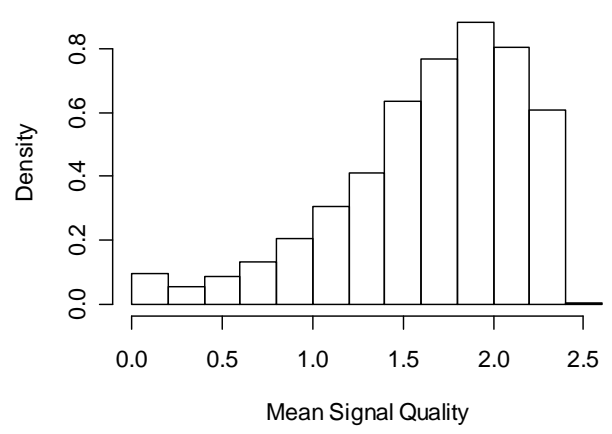

S.D across households

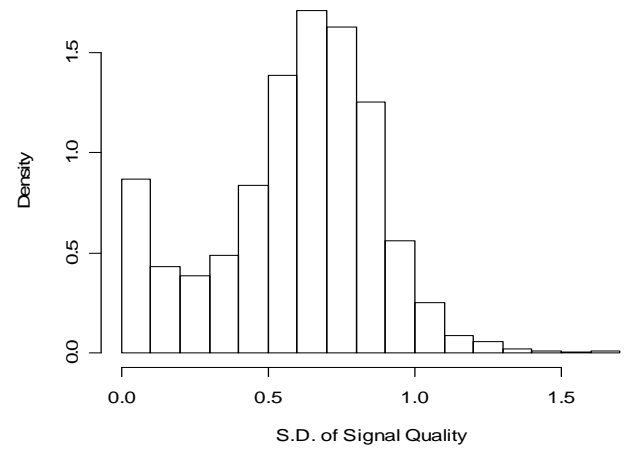

Figure 2: Signal Quality Pattern




Figure 3a: Activation

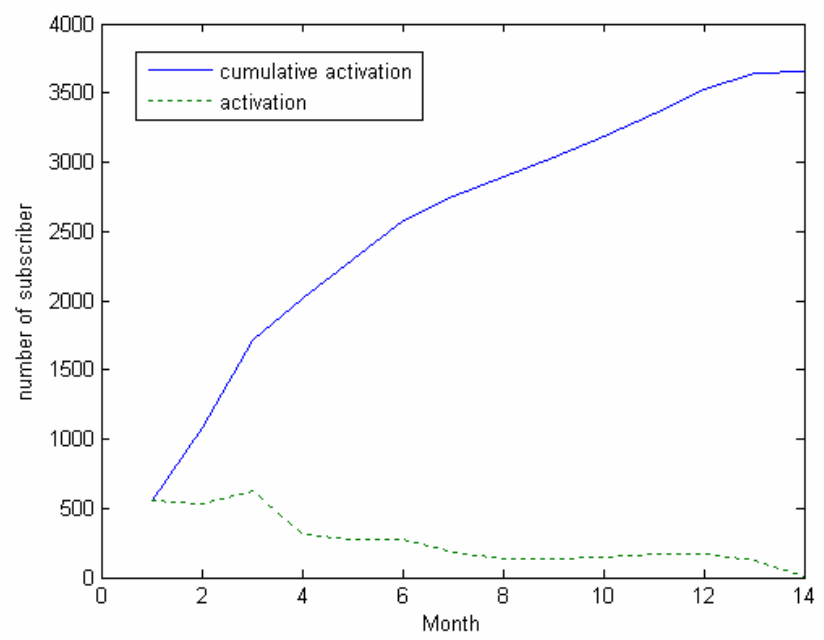

Figure 3b: Termination

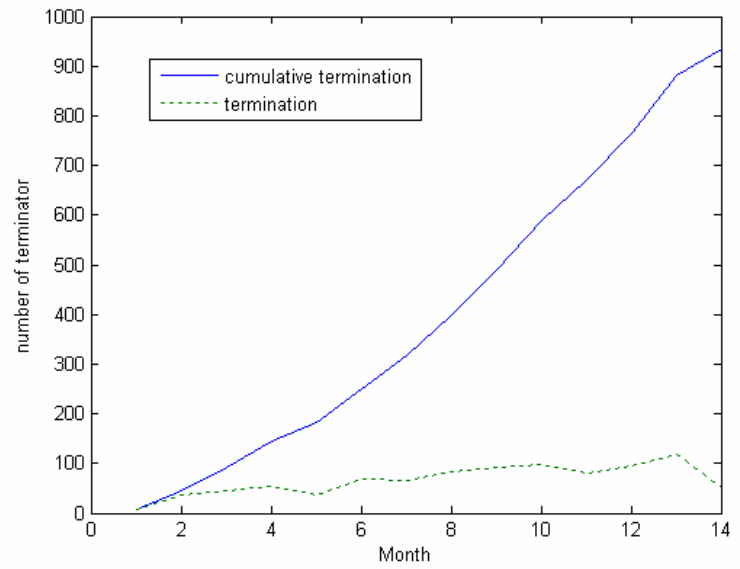

Figure 3c: Movie Rental

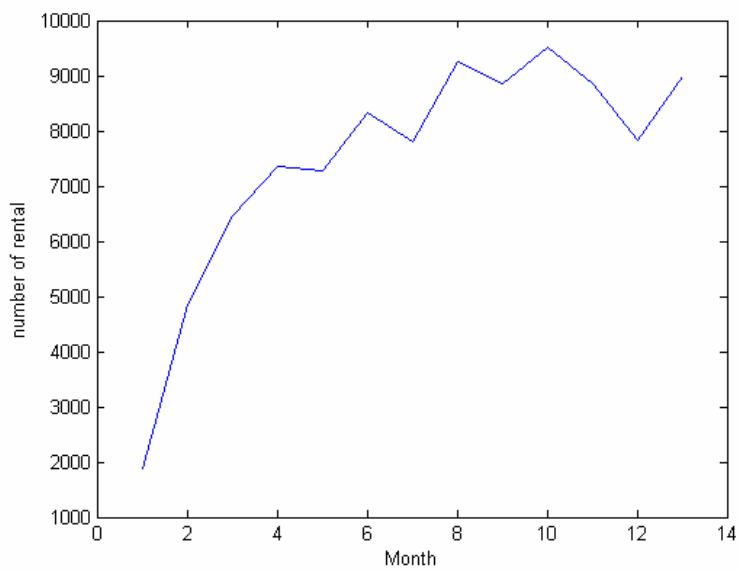


Figure 4a: Number of movie rentals by signal level

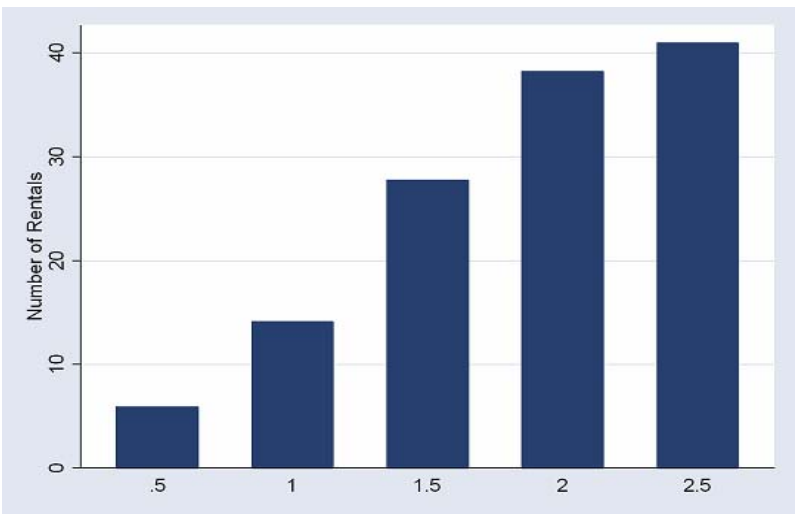

Figure 4b: Termination rates by signal level

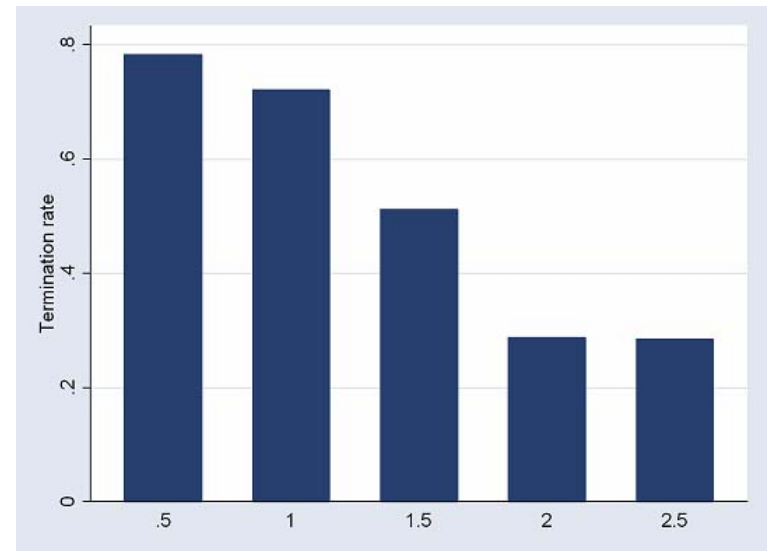

Figure 4c: First 6 month rental patterns by signal level

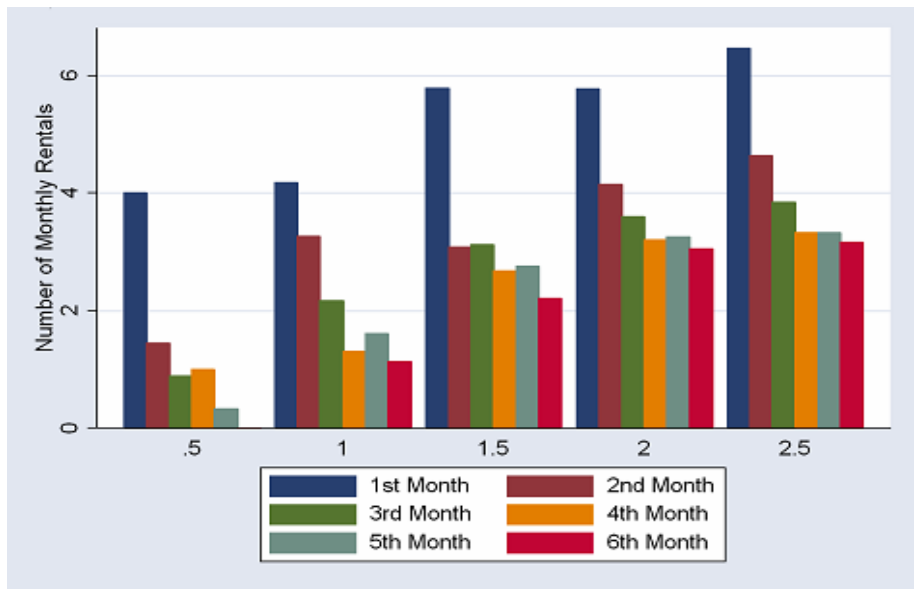


Figure 5: Spatial pattern of subscribers

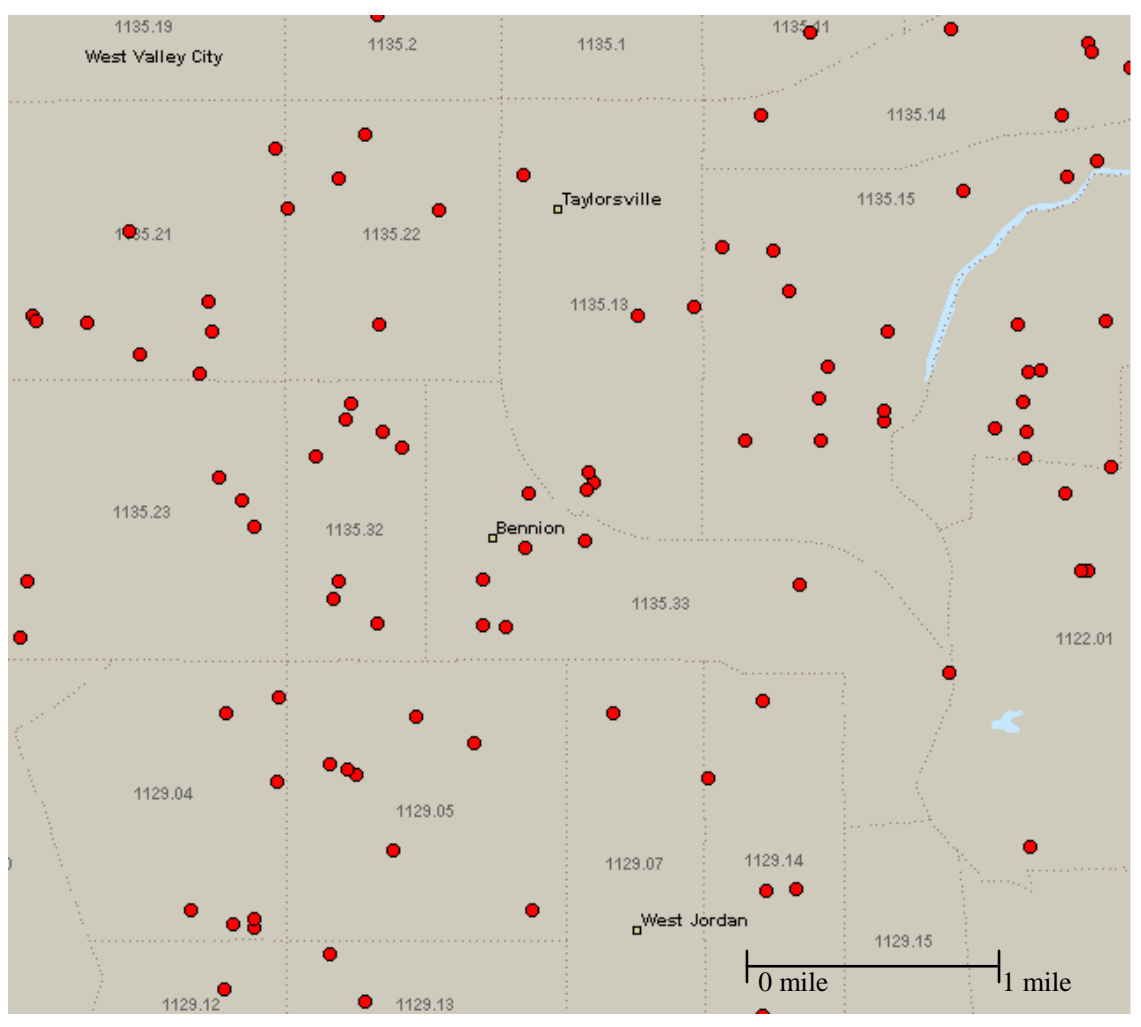


Figure 6: Income distribution pattern



Figure 7: Satellite Picture of an area in Salt Lake City

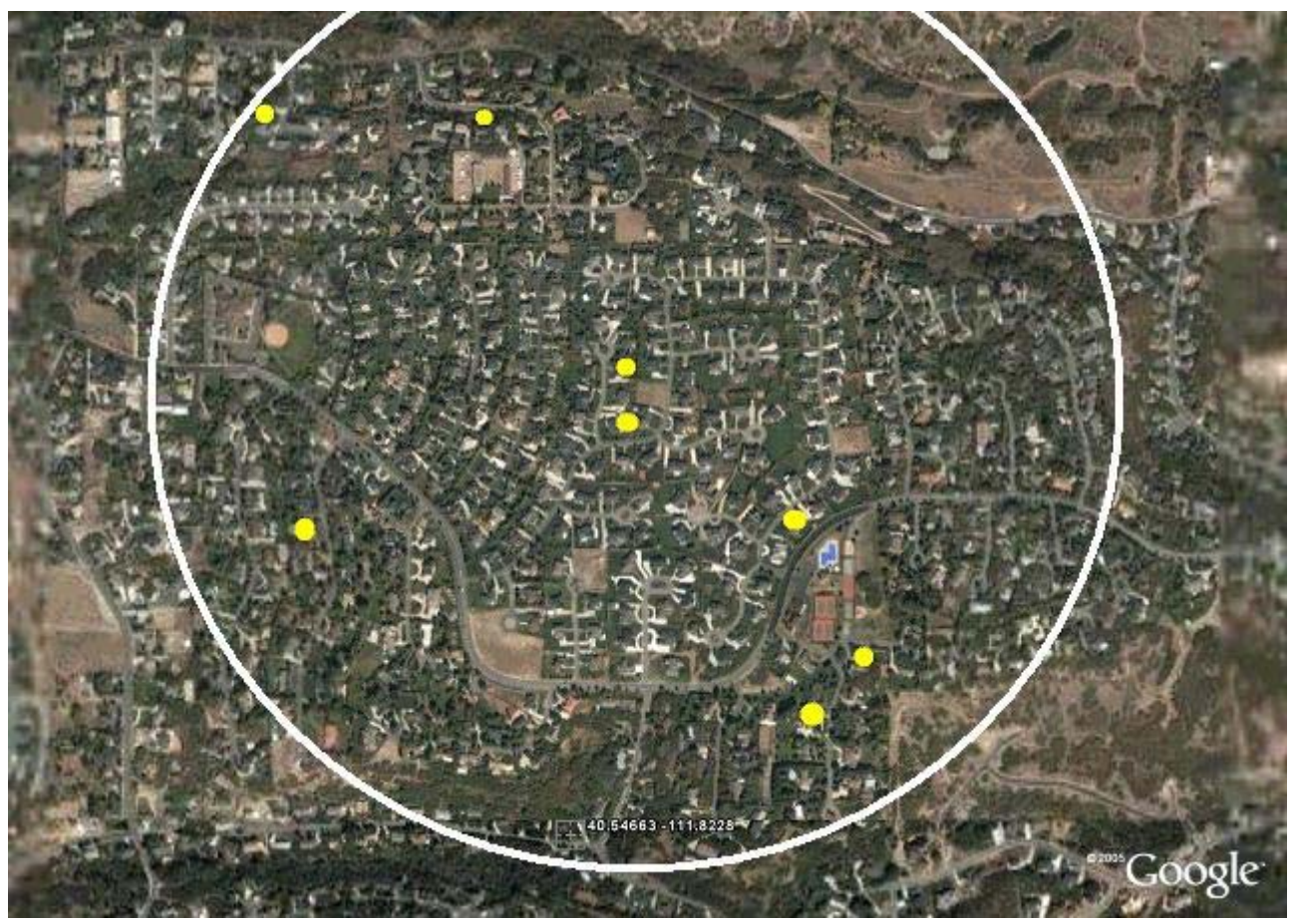


Figure 8a: Activation baseline hazard by segment
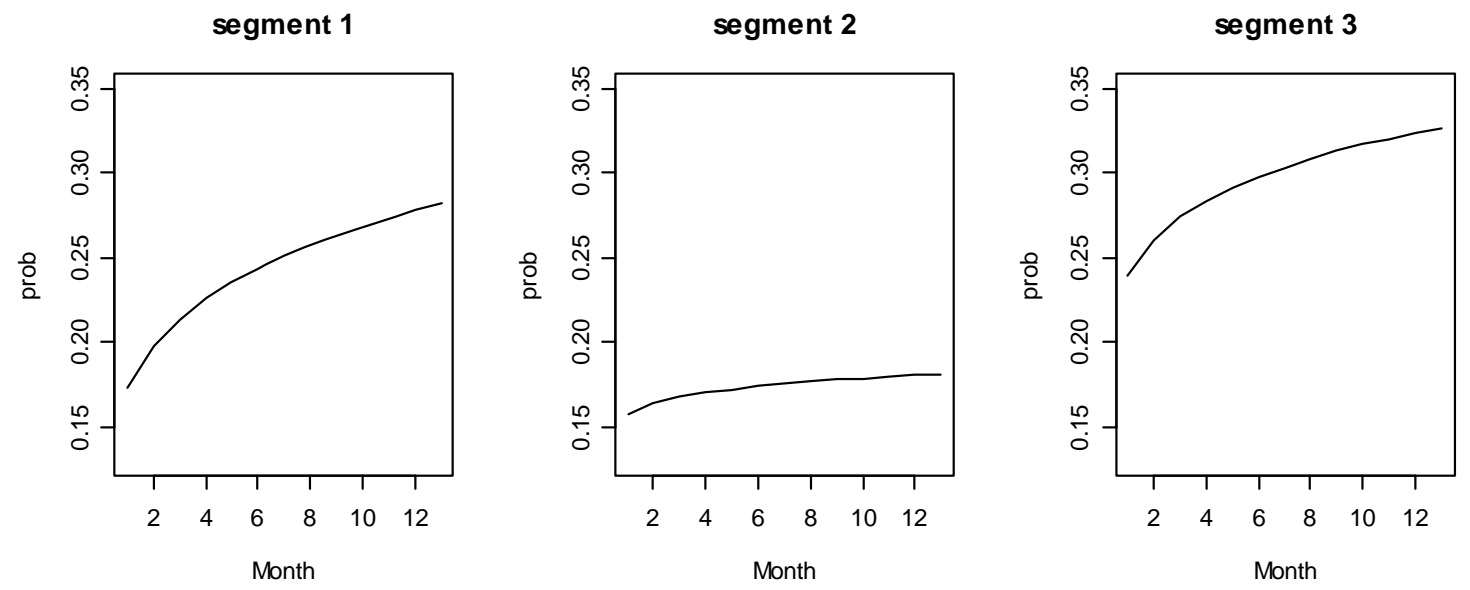

Figure 8b: Actual activation pattern by segment

Figure 9a: Termination baseline hazards by segment
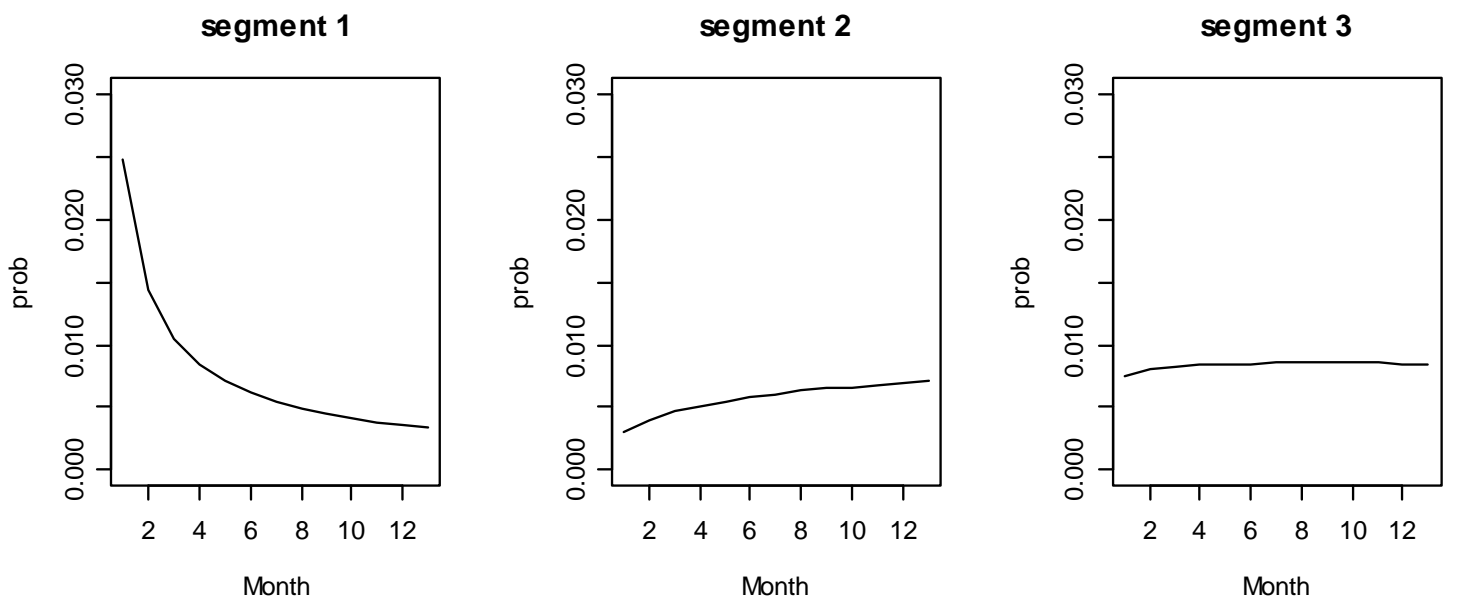

Figure 9b: Actual termination pattern by segment
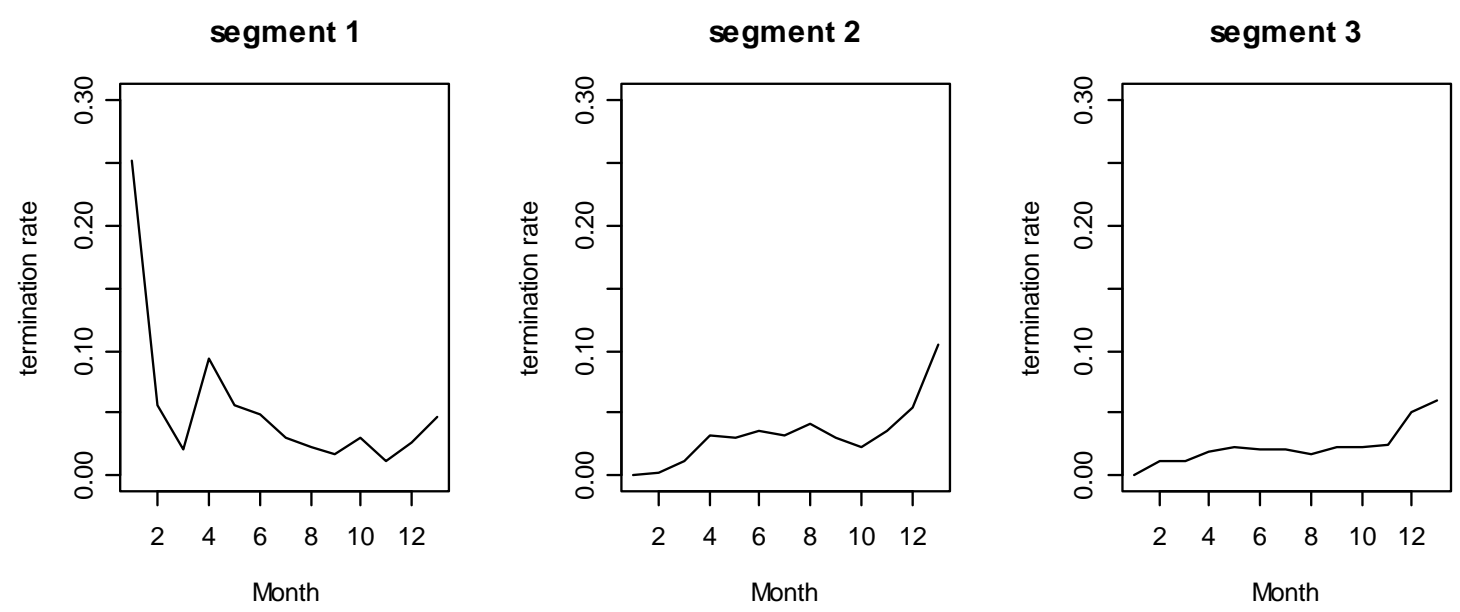
Figure 10a: Rentals over time by segment
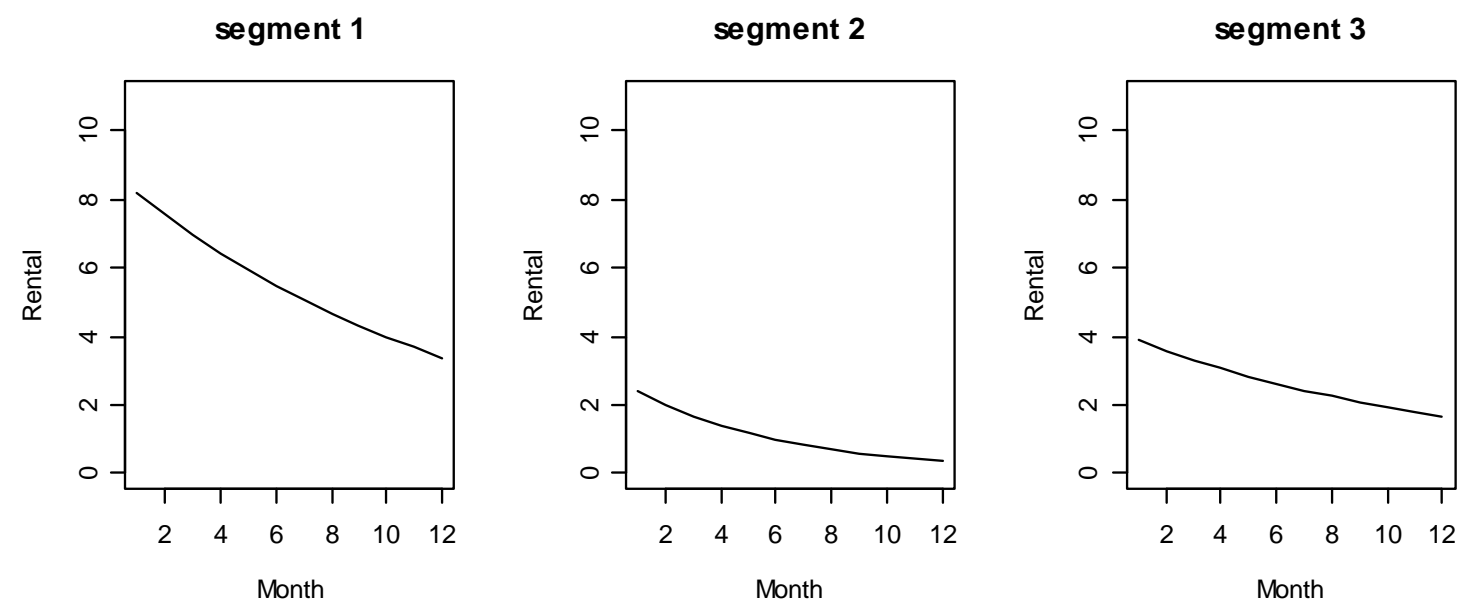

Figure 10b: Actual rentals over time by segment
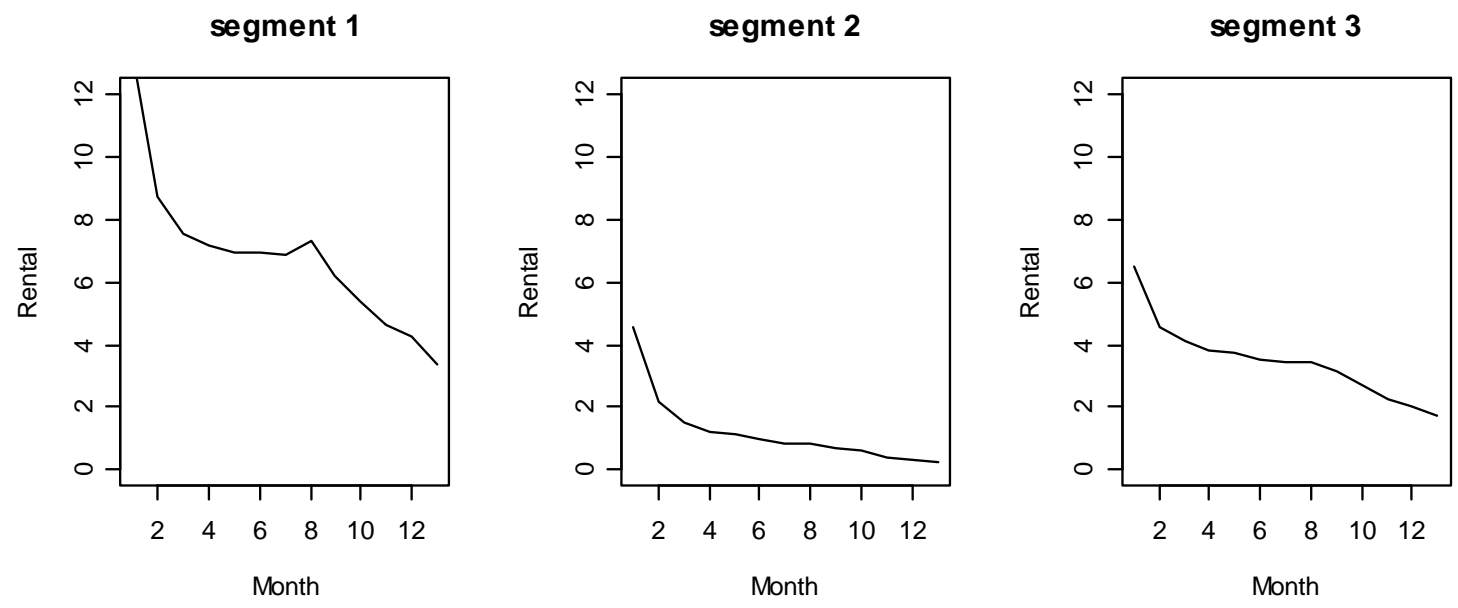
Figure 11: Predicted rentals by segment

Figure 12: Incremental Adopters over Time when Service Quality is Improved (Indirect Effect)

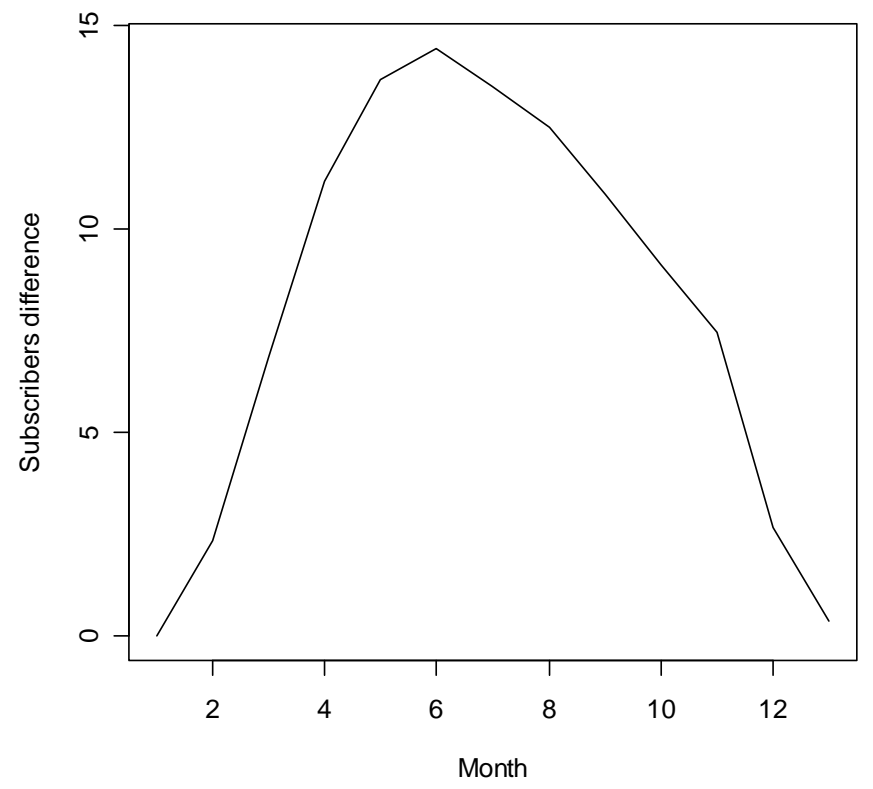

Figure 13: Incremental Adopters over Time when Word of Mouth is all "Good" relative to all "Bad"

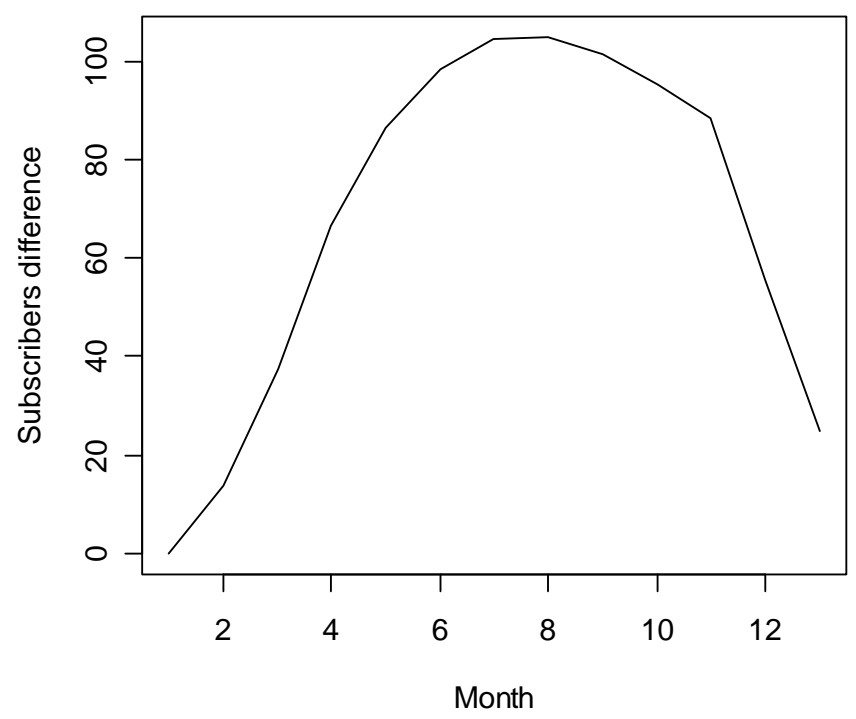

